BNL - 49384

Informal Report

Performance of Carbon-Based Hot Frit Substrates

I. Low Pressure Helium and Hydrogen Testing

R. Barletta, J. Adams, J. Svandrik and J. R. Powell

April 11, 1991

Published July, 1993

Reactor Systems Division Department of AdvancedTechnology

Brookhaven National Laboratory

Upton, NY 11973

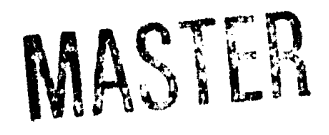




\begin{abstract}
The performance of various carbon-based materials in flowing, high-temperature helium and hydrogen is described. These materials which are candidate hot frit substrates for possible application in a PBR include various grades of graphite, carbon-carbon and vitreous carbon. Vitreous carbon showed extremely good performance in helium, while that of the various graphite grades was quite variable and, in some cases, poor. Purified grades performed better than unpurified grades, but in all cases large sample-to-sample variations in weight loss were observed. For carbon-carbon samples, the performance was intermediate. Since the weight loss in these samples was in large measure due to the loss of the densification media, improvements in the performance of carbon-carbon may be possible. With respect to the performance in hydrogen, high weight losses were observed, reenforcing the need for coating carbon-based materials for service in a flowing hydrogen environment.
\end{abstract}




\section{CONTENTS}

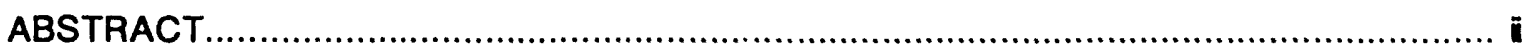

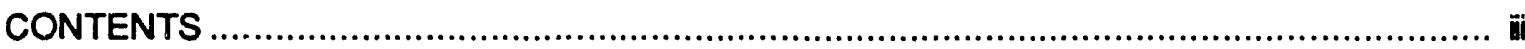

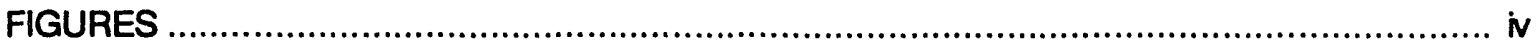

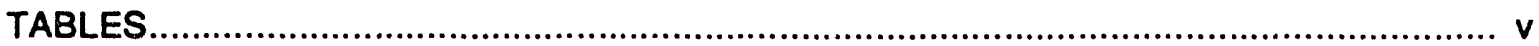

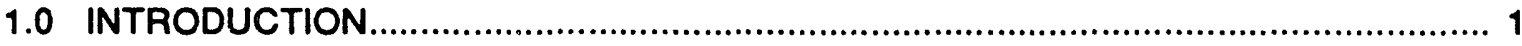

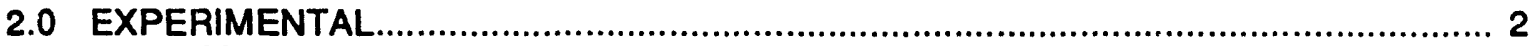

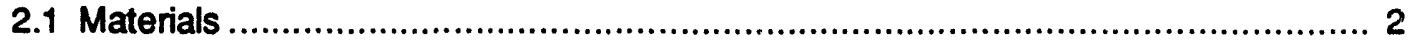

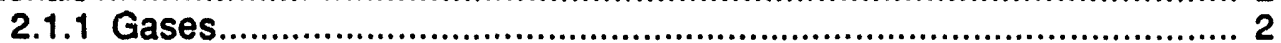

2.1.2 Graphite .......................................................................... 2

2.1.3 Vitreous Carbon.................................................................... 4

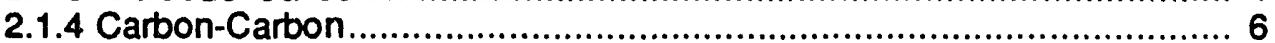

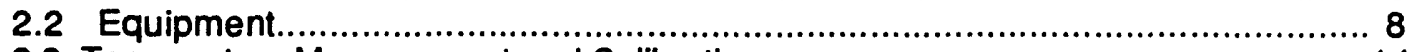

2.3 Temperature Measurement and Calibration ...........................................11

2.4 Test Procedure ............................................................................ 15

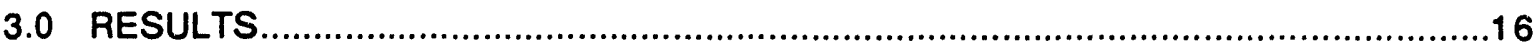

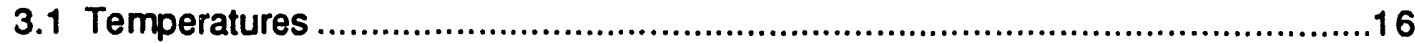

3.2 Hydrogen Tests ............................................................................ 16

3.3 Helium Tests ........................................................................

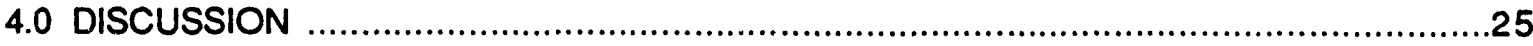

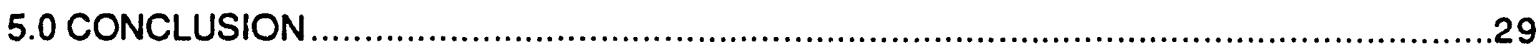

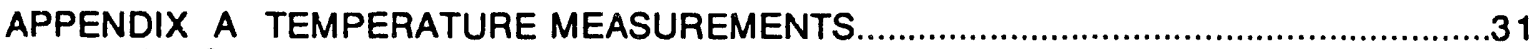

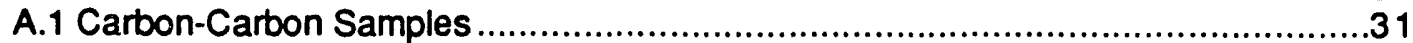

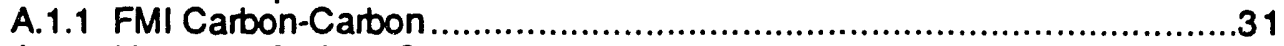

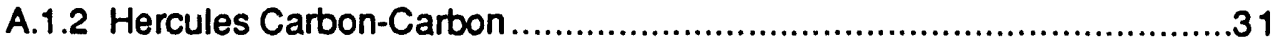

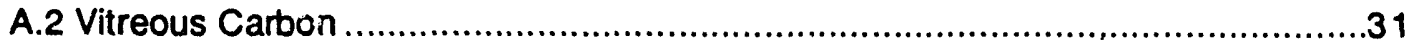

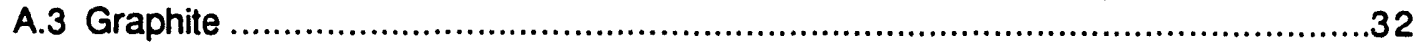

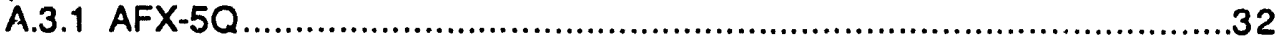

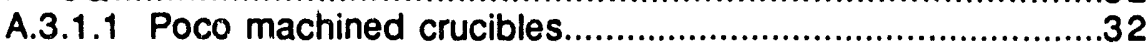

A.3.1.2 BNL machined crucible (AFX-5Q') .............................32

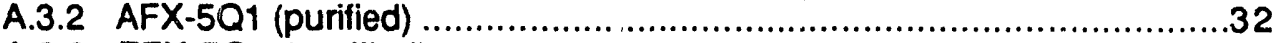

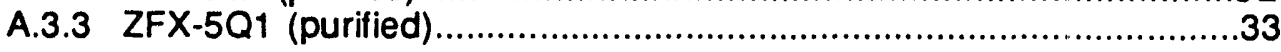

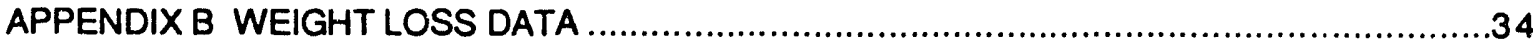

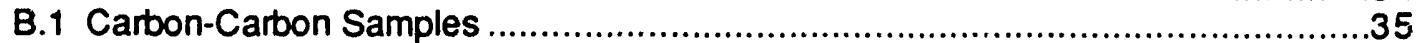

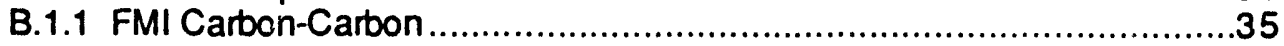

B.1.2 Hercules Carbon-Carbon .....................................................

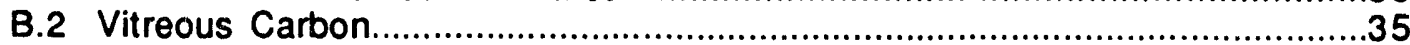

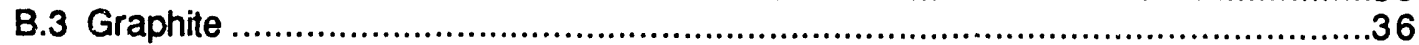

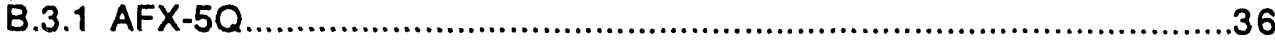

B.3.1.1 Poco machined crucibles..............................................36

B.3.1.2 BNL machined crucible (AFX-5Q*) ...........................36

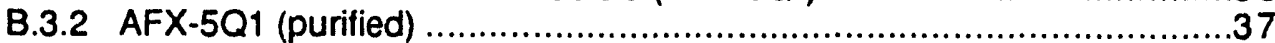

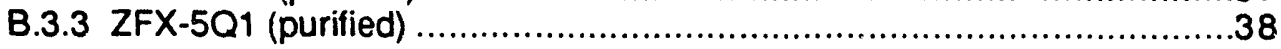




\section{FIGURES}

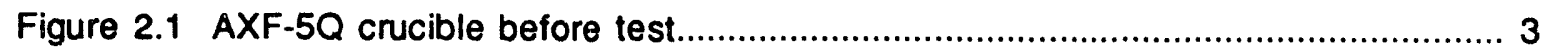

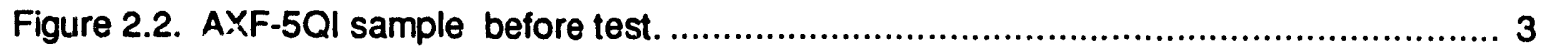

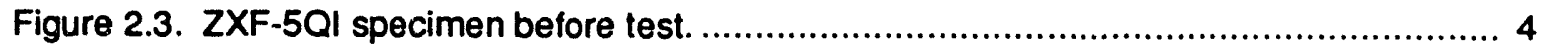

Figure 2.4. Vitreous carbon (grade V25) specimen before test.......................................... 5

Figure 2.5. FMA carbon-carbon specimen before test...................................................... 6

Figure 2.6. Hercules carbon-carbon specimen before test ............................................. 7

Figure 2.7. Lower portion of induction heater showing the lower portion of the quartz jacket, the BN and graphite tubes and graphite susceptor

Figure 2.8. Overall view of induction heater showing the coil, outer quartz jacket and end fittings.

Figure 2.9. Typical calibration curve for range 1 of an optical pyrometer.

Figure 3.1. Weight loss from vitreous carbon (grade V25) and carbon-carbon after exposure to hydrogen.

Figure 3.2. Vitreous carbon (grade V25) specimen after 15 minutes in hydrogen.

Figure 3.3. Carbon-carbon specimen after 5 minutes in hydrogen. .18

Figure 3.4. Weight losses in helium from (a) carbon-carbon and vitreous carbon samples.......19

Figure 3.5. Changes in surface area observed for samples heated in flowing helium.............20

Figure 3.6. FMI carbon-carbon sample after heating in helium for 90 minutes. .21

Figure 3.7. Hercules carbon-carbon sample after heating in helium for 40 minutes. .22

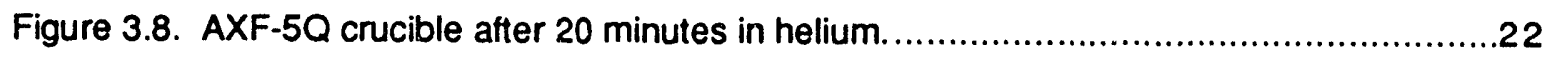

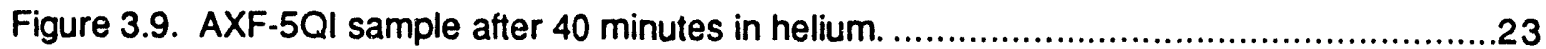

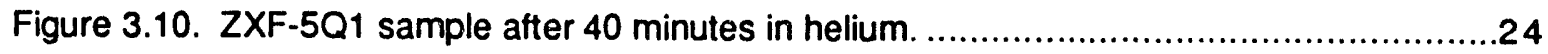

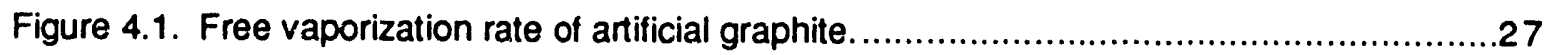




\section{TABLES}

Table 2.1. Properties of vitreous carbon grade V25 (obtained from Atomergic Chemetal catalog)

Table 2.2. Typical "A" values for pyrometer calibration. Data taken for Pyrometer No. 252 which was calibrated on $3 / 9 / 90$

Table 2.3 Results of melting point tests. 14

Table 3.1 Mean temperatures for test specimens. .16

Table 4.1. Amount of gas desorbed from specimens in helium tests using data in

Reference 6.

Table 4.2. Estimates of the maximum anticipated weight loss due to carbon vaporization. .26 
Performance of Carbon-Based Hot Frit Substrates

1. Low Pressure Helium and Hydrogen Testing"

\subsection{INTRODUCTION}

As a part of developmental work on components for particle bed reactors (PBR), several alternatives have been investigated for hot frits. These alternatives have included monolithic materials such as boron nitride as well as woven composites. Most of the effort thus far has focused on carbon-based materials such as graphite and carbon-carbon. Although these materials would appear to be promising from the standpoint of providing extremely high temperature performance, it is recognized that for PBR applications which require the use of hydrogen at high temperatures, protection of these carbon-based hot frits through hydrogen resistant coatings will be required. Still, the baseline performance of uncoated materials is of interest in order to obtain the most robust design possible.

In light of this goal, experiments have been conducted on a variety of potential carbonbased substrates. Performance of a variety of graphites, vitreous carbon, and carbon-carbon composites has been investigated at high temperature in flowing helium and hydrogen. Weight losses and dimensional changes have been measured as a function of time. Initial work has been screening in nature. In particular, while the temperatures are felt to be prototypical, pressures and flow rates are not. Further, the mechanical properties of these materials at temperature, while of interes: and importance in design, have not been measured at this time. Rather the goal of this work was to establish a basis for selection of candidate hot frit substrates for future development work using existing techniques and equipment. Development of advanced techniques for high pressure testing of materials related to prototypic PBR conditions is clearly required especially as design of such systems mature. Mechanical properties need to be measured as well as the performance of hot frits at or near full-scale. Even granted the limited scope of the testing reported herein, however, the results are valuable for narrowing the number of candidate materials which would merit further testing and development work.

The purpose of this report within this context is multifold. First, it is desirable to summarize the experimental techniques used in these screening tests. Documentation of procedures for testing as well as temperature calibration are necessary. Secondly, this report seeks to summarize the performance of these candidate substrates in the test environments. Finally, based upon these results, directions for future hot trit development work will be indicated. As this work is part of an on-going program here at BNL, the results are preliminary and will be used as a guide for future efforts.

\footnotetext{
Research performed under funding provided by the US Air Force's Philipps Laboratory Space Nuclear Thermal Propulsion Program, Proposal No. PL.STX-92-00
} 


\subsection{EXPERIMENTAL}

\subsection{Materials}

\subsubsection{Gases}

Three gases were used in this work: argon, helium and hydrogen. Argon and helium were used as outside cover gases between the susceptor and quartz jacket. Helium and hydrogen were used as test gases inside the susceptor (see Section 2.2). Argon cover gas was prepurified grade $(99.998 \%$ purity). Prior to introduction into the induction furnace, the outside cover gas was further purified by passing it through a tube full of calcium metal turnings which was kept at $\sim 650^{\circ} \mathrm{C}$ for the removal of any residual oxygen and water from the gas. The helium and hydrogen used in these experiments was obtained from Spectra Gases Inc. The helium was RG grade $(99.9999 \%$ purity). The hydrogen purity was $99.9995 \%$. Gases supplied to the susceptor were further purified by passing the gas through a coil containing molecular sieves and activated charcoal which was immersed in liquid nitrogen.

\subsubsection{Graphite}

The performance of three types of graphite have been investigated. Two of the grades tested were "purified", i.e. treated with chlorine gas to remove metals, by the manufacturer. All three have been obtained from Poco Graphite. The first graphite studied was AXF-5Q. A large amount of data was collected on this graphite since it was used as the base material for crucibles for the induction furnace. The crucibles used were either fabricated by Poco Graphite or fabricated in-house from graphite stock. The Poco graphite crucibles were cyclindrical with the following nominal dimensions : $0.375^{\prime \prime}$ i.d. $\times 0.345^{\prime \prime}$ deep with a $0.031^{\prime \prime}$ wall. In the bottom of each crucible 5 small holes were drilled to admit gas. The initial surface area of the crucibles was very reproducible. Based upon measurement of eight crucibles the geometric surface area was $7.87 \pm$ $0.02 \mathrm{~cm}^{2}$, neglecting the holes in the bottom. Data was also taken on a crucible of similar dimensions made of AXF-5Q stock here at BNL. While the initial surface area of this crucible was not measured, it may be assumed to be roughly the same as those made by Poco. A photograph of a Poco crucible is shown in Figure 2.1

Data was also obtained on the purified grade of AXF-5Q which is denoted as AFX-5QI. Four specimens were tested in He. The nominal sample size was a square $0.25^{\prime \prime}$ by $0.05^{\prime \prime}$ thick. The average initial surface area of these samples was $1.3 \pm 0.1 \mathrm{~cm}^{2}$. A typical pretest specimen is shown in Figure 2.2.

The third type of graphite tested was Poco's grade ZXF-5OI which was also a purified grade. These samples were cylindrical, nominally $0.375^{\prime \prime}$ diameter $\times 0.1$ " high. A total of three samples were tested in helium with an average initial surface area of $2.319 \pm 0.003 \mathrm{~cm}^{2}$ (neglecting holes). A pretest specimen is shown in Figure 2.3. 

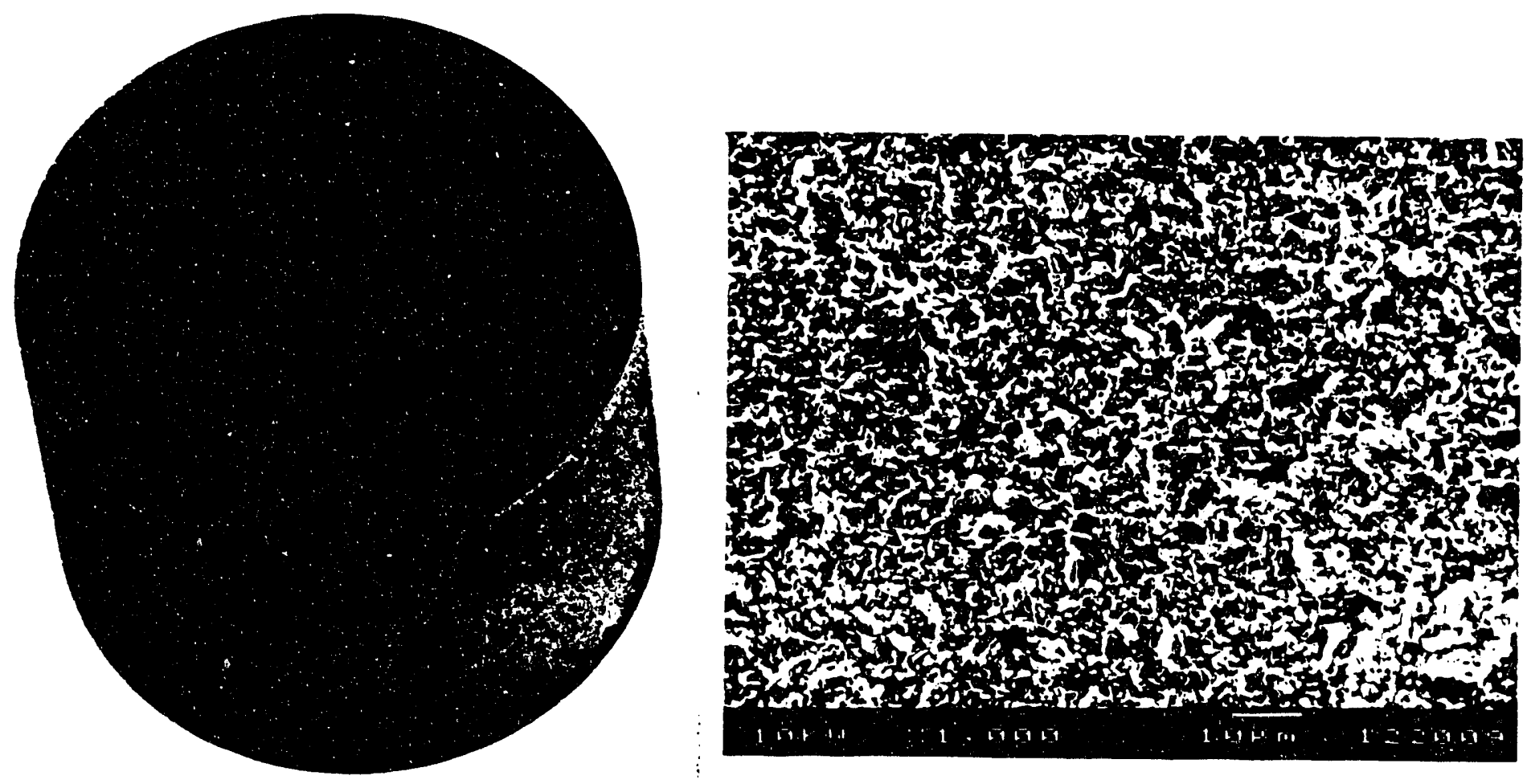

Figure 2.1. AXF-5Q crucible before test.
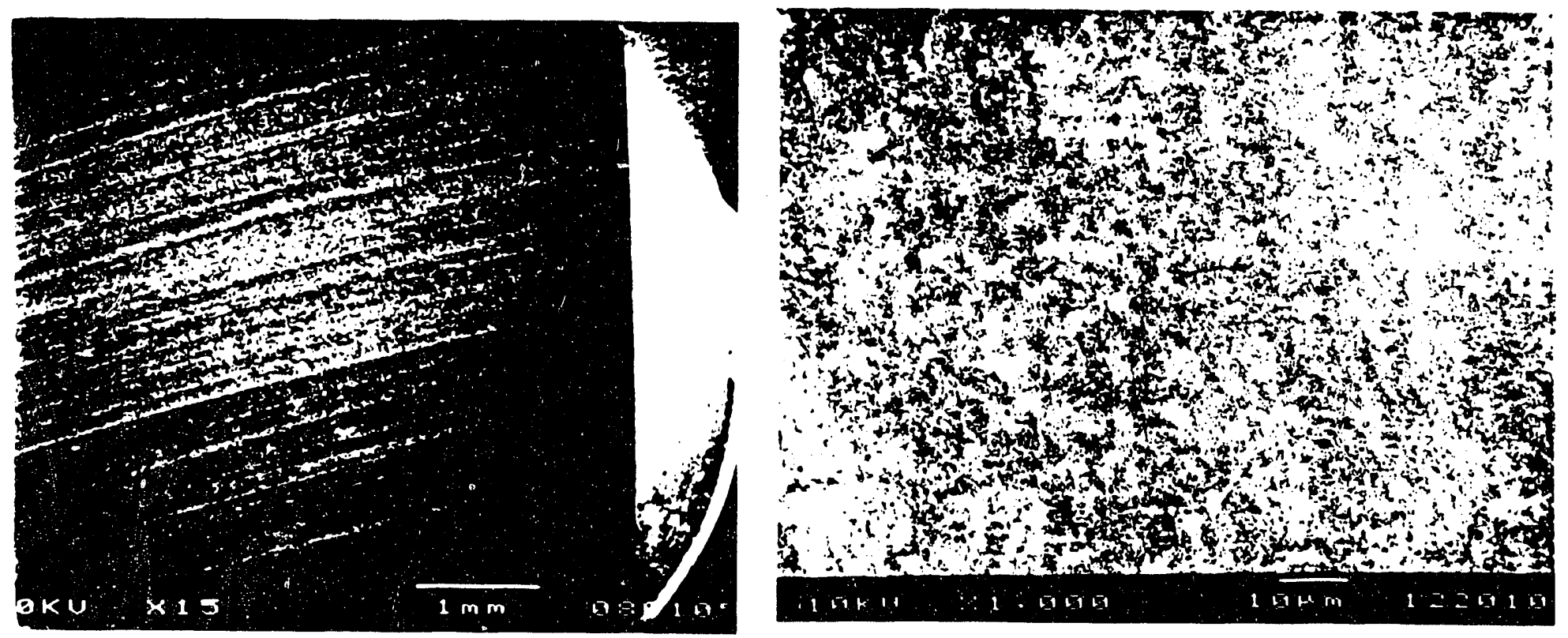

Figure 2.2. AXF-5QI sample before test. 

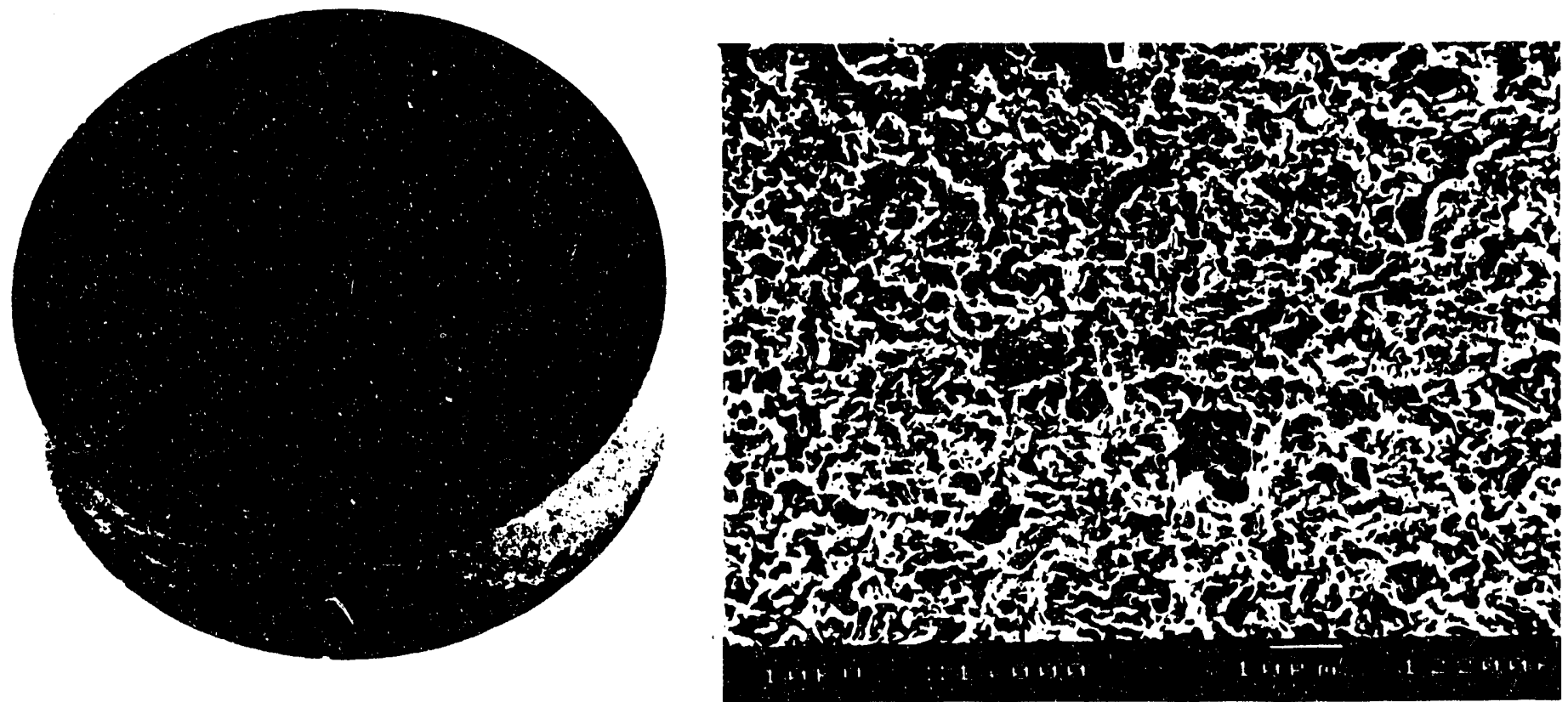

Figure 2.3. ZXF-5QI specimen before test.

\subsubsection{Vitreous Carbon}

Tests on vitreous carbon samples were pertormed in both hydrogen and helium. The vitreous carbon was obtained from Atomergic Chemetals $\mathrm{Co}$. The material used was their grade V25 which has been heat treated to $2500^{\circ} \mathrm{C}$. A list of properties for this material is given in Table 2. For the hydrogen tests initial dimensions were $0.2375^{\prime \prime} \times 0.2425^{\prime \prime} \times 0.085^{\prime \prime}\left(1.27 \mathrm{~cm}^{2}\right)$ while for the helium tests, the initial sample dimensions were $0.210^{\prime \prime} \times 0.234^{\prime \prime} \times 0.079^{\prime \prime}\left(1.09 \mathrm{~cm}^{2}\right)$. A pretest specimen is shown in Figure 2.4 

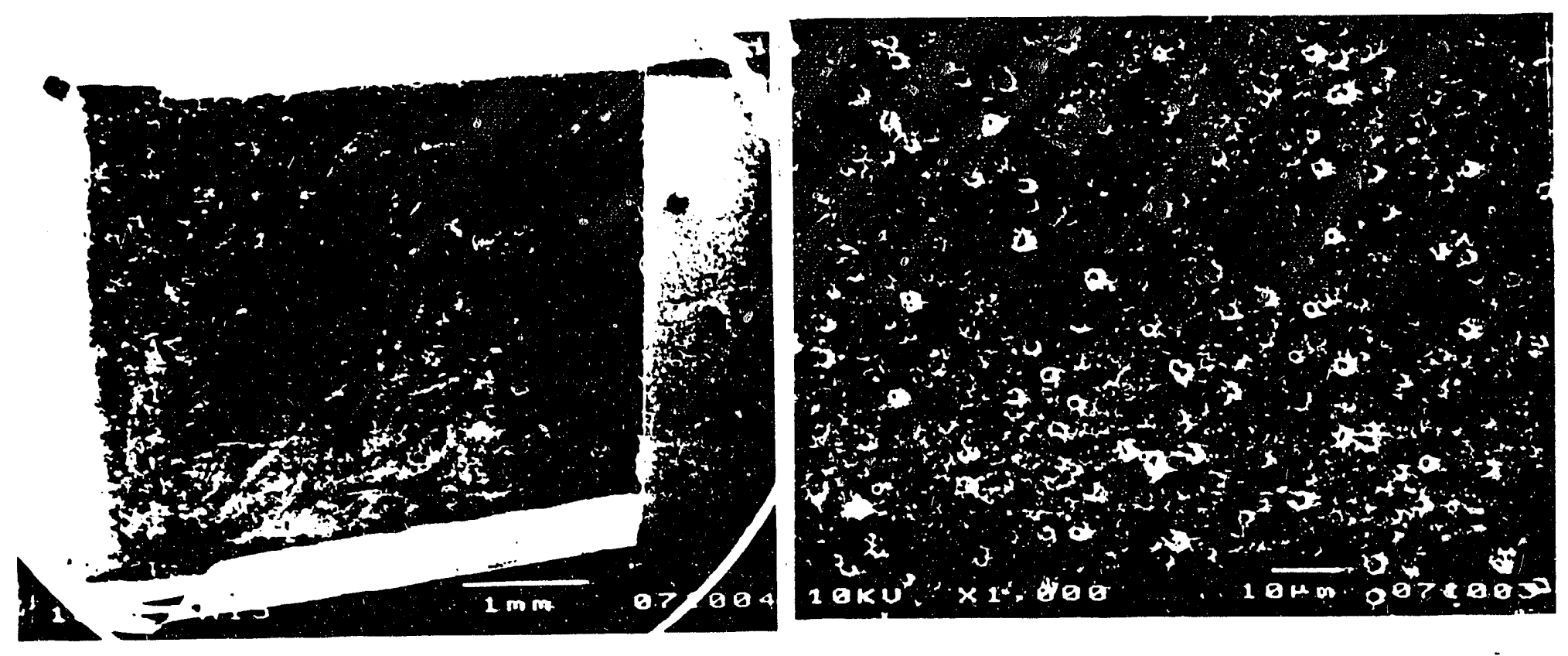

Figure 2.4. Vitreous carbon (grade V25) specimen before test.

Table 2.1. Properties of vitreous carbon grade V25 (obtained from Atomergic Chemetals catalog).

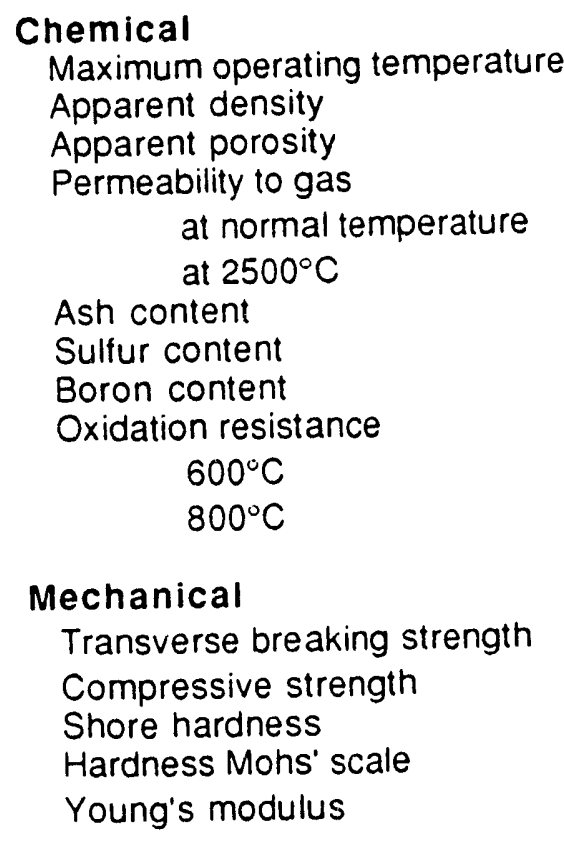

$>2500^{\circ} \mathrm{C}$

1.50 to 1.55

0

better than $10^{-8} \mathrm{~cm}^{2} / \mathrm{s}$

approximately $10^{-6} \mathrm{~cm}^{2} / \mathrm{s}$

$0.005 \%$ (50 ppm)

$<50 \mathrm{ppm}$

$<2 \mathrm{ppm}$

$0.1 \mathrm{mg} / \mathrm{cm}^{2} / \mathrm{h}$

600 to $800 \mathrm{~kg} / \mathrm{cm}^{2}$

1500 to $2000 \mathrm{~kg} / \mathrm{cm}^{2}$

6-7

150-175

$2200 \mathrm{~kg} / \mathrm{mm}^{2}$ 
Table 2.1 (cont.). Properties of vitreous carbon grade V25 (obtained from Atomergic Chemetals catalog).

\author{
Thermal \\ Coefficient of thermal expansion \\ $100^{\circ} \mathrm{C}$ \\ $650^{\circ} \mathrm{C}$ \\ $3.2 \times 10^{-6}$ by ${ }^{\circ} \mathrm{C}$ \\ $3.5 \times 10^{-6}$ by ${ }^{\circ} \mathrm{C}$ \\ Thermal conductivity /Resistance to thermal shock $0.06 \mathrm{cal} / \mathrm{cm} / \mathrm{s} /{ }^{\circ} \mathrm{C}$ \\ Air quenching acceptable from ....to RT \\ $2500^{\circ} \mathrm{C}$ \\ Electrical \\ Resistivity \\ $4500 \mu \mathrm{hm} / \mathrm{cm}$
}

\title{
2.1.4 Carbon-Carbon
}

Two types of carbon-carbon were tested. The first was from prototype hot frit material fabricated by Fiber Materials Incorporated (FMI) as a part of thermal hydraulic testing here at BNL. The samples were cut from a large piece which had been rabricated from Apollo 55 fibers densified with pyrolytic carbon and heat teated to $2550^{\circ} \mathrm{C}$ for one half hour. The samples contained slots which had been laser drilled. Samples were nominally 0.25 " square and 0.09 " thick. Single samples were tested in hydrogen and helium. The initial dimensions of the hydrogen test specimen were nominally $0.245^{\prime \prime} \times 0.253^{\prime \prime} \times 0.09 "$ and for the helium test specimen was $0.249^{\prime \prime} \times 0.250 " \times 0.093^{\prime \prime}$. Neglecting the laser drilled slots the geometric surface areas of these samples were 1.38 and $1.40 \mathrm{~cm}^{2}$, respectively. A typical pretest specimen is shown in Figure 2.5 .
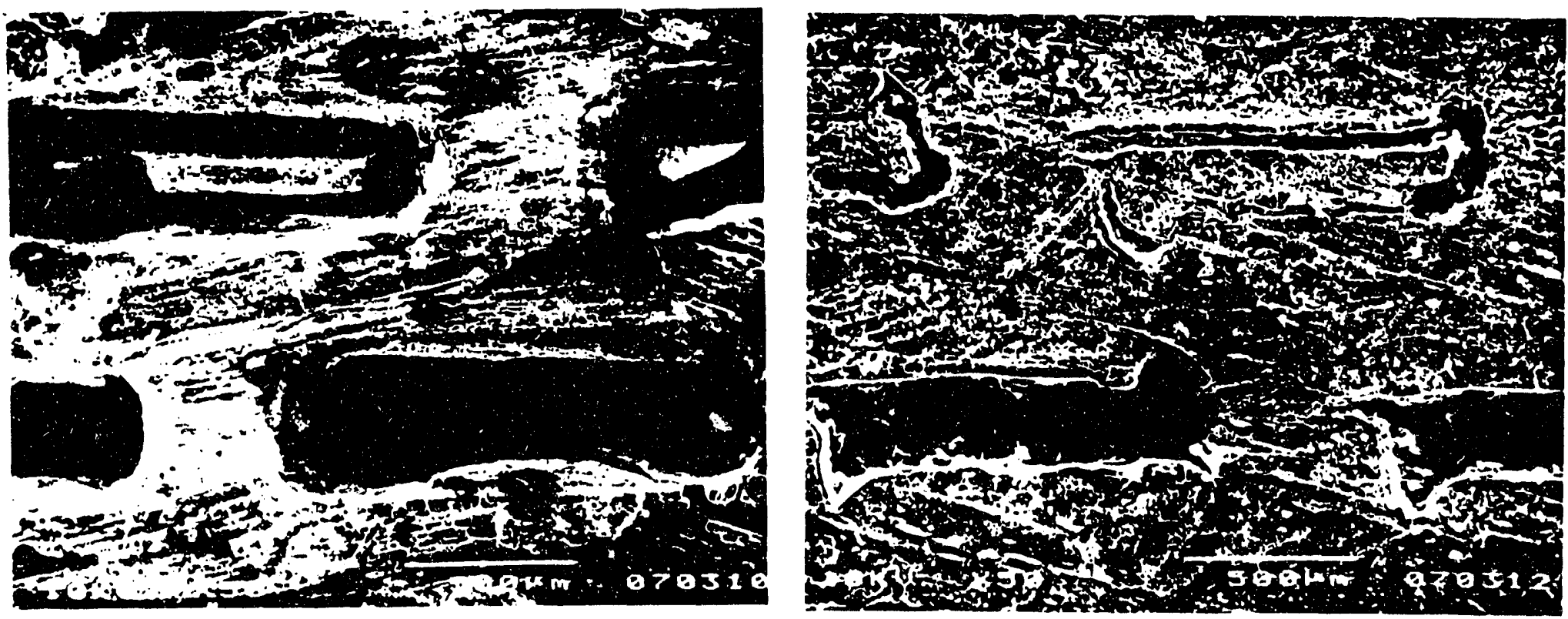

Figure 2.5. FMI carbon-carbon specimen before test. 
The second type of carbon-carbon tested was obtained from Hercules and was a 3-D carbon-carbon weave. The samples were cylindrical in shape, measuring nominally $0.25^{\prime \prime}$ diameter by 0.25 " high. Each sample had three small holes drilled lengthwise through it. The average surface area of samples before testing was $1.90 \pm 0.01 \mathrm{~cm}^{2}$, neglecting these holes. This value was based upon the measurement of 5 samples, two of which were subsequently tested in helium. A total of three samples were included in the helium testing. A typical pretest specimen is shown in Figure 2.6.
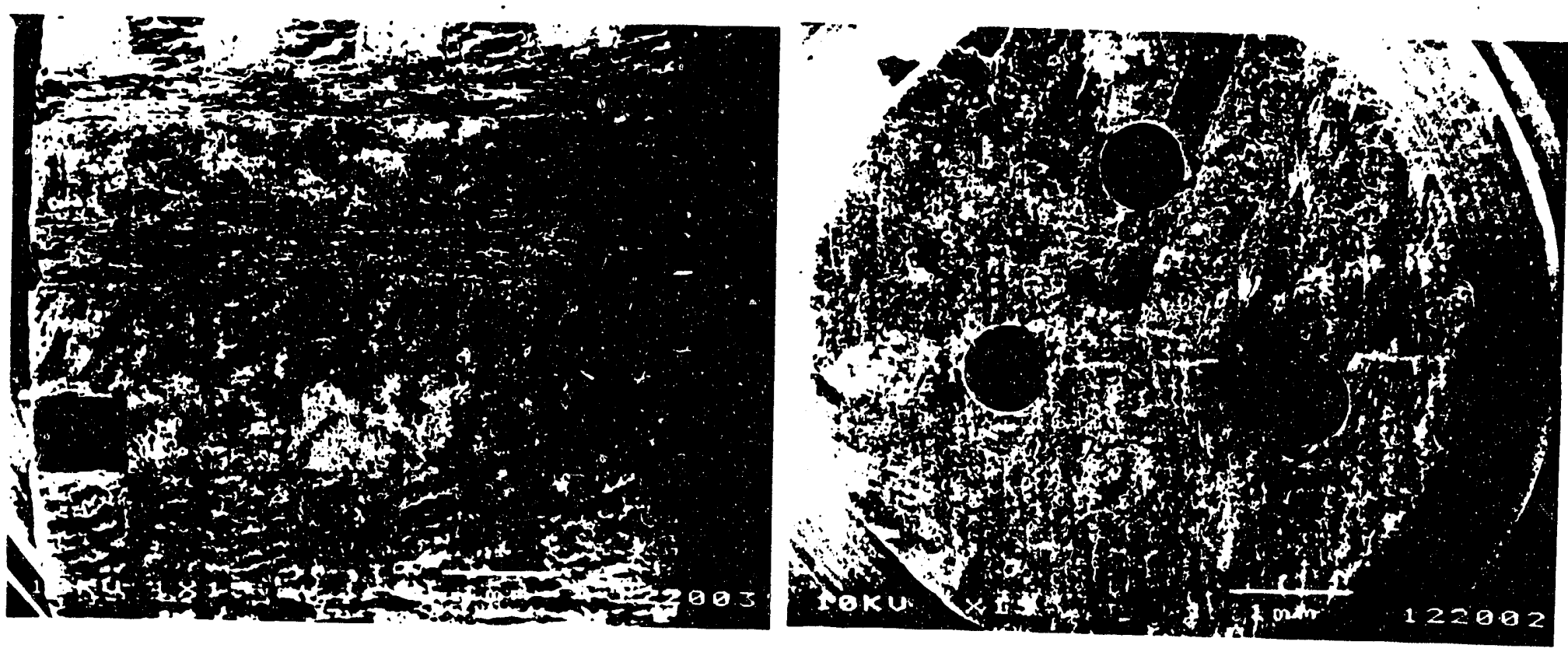

Figure 2.6. Hercules carbon-carbon specimen before test. 


\subsection{Equioment}

High temperature materials tests have thus far been conducted using a high-frequency induction furnace under flowing gas conditions. The furnace design was based on a readily available RF generator and an initial system description has been given previously. ${ }^{1}$ The solid state power supply was a Lepel Model T-1--3-KC-TL, which produces RF output at $10 \mathrm{~kW}$ at 200 . $450 \mathrm{kHz}$. The water-cooled outfeed provided was 1/4" copper tubing. Optimum heating was found to occur using a load coil of 3/16" copper tubing of 30 turns which was close fitted around a $30 \mathrm{~mm} \times 4.5 \mathrm{~mm}$ wall ', uartz tube which served as the outer pressure boundary of the induction heater. Within this tube, the atmosphere was kept inert by flowing purified argon or helium (see Section 2.1.1) at a pressure of approximately $12-15 \mathrm{psig}$ and a flow rate of $\sim 7 \mathrm{cc} / \mathrm{s}$. The use of argon as a cover gas was discontinued in favor of helium when a persistent yellow flame was observed at the top of the susceptor at low temperatures during heat up. The cause of this flame is unknown. Use of He has eliminated it, however. The primary coil coupled to a graphite susceptor (3/4" O.D. $x \sim 1 / 2 "$ I.D. $x \sim 11 / 2 " H$ ) containing a graphite crucible, the latter serving as a holder for the sample being tested. The susceptor, crucible and other structural pieces were typically machined from AF $i-5 Q$ graphite. The crucible dimensions are given in Section 2.1.2. For experiments performed in hydrogen, all exposed graphite was coated with $\mathrm{TaC}$. For those experiments performed on Poco ZXF5QI graphite, the crucible was omitted. Instead, samples were placed on a TaC-coated graphite disk. Like the crucible, this disk also had holes in the bottom to distribute the gas flow. The susceptor was covered with a graphite disk to prevent loss of the sample from the open crucible and to reduce radiant heat loss. Temperature measurements were made by sighting an optical pyrometer (Pyrometer Instrument Co.) through an "/8" hole in this cover disk.

The susceptor was supported to mid-height of the load coil by a graphite tube which in turn fitted into a hot-pressed boron nitride tube. These tubes also served as a duct for a calibrated gas flow to the interior of the susceptor of either helium or hydrogen. This flow came up through a machined aluminum fitting which supported the outer quartz jacket and provided ducting for the exit gas flow. A photograph showing the lower portion of the quariz izcket, the $\mathrm{BN}$ and graphite tubes and graphite susceptor is shown in Figure 2.7.

'R. E. Barletta, R E Davis, J W Adams and J. R. Powell, Materials Compatibility and Test Development, June 1989 


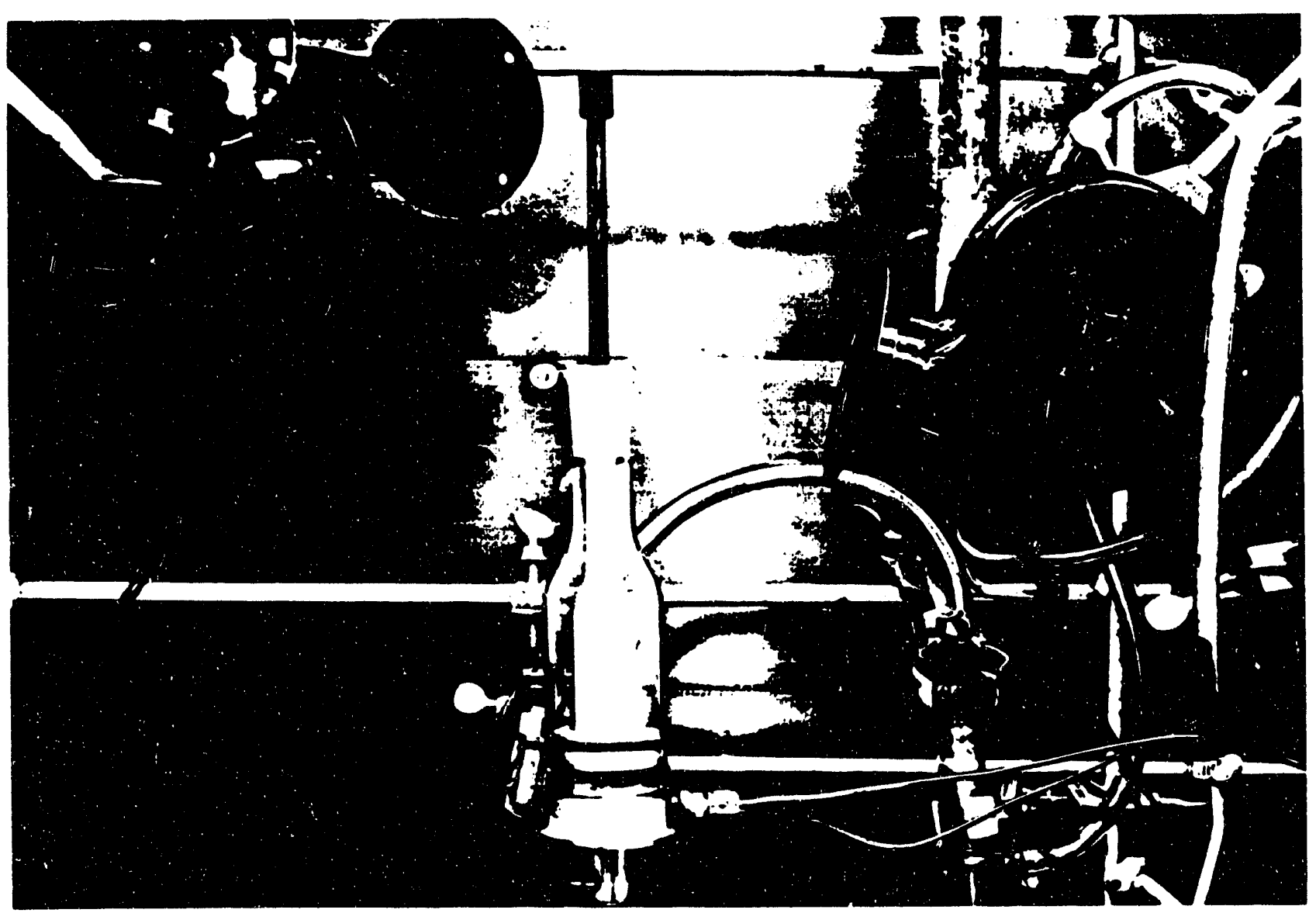

Figure 2.7. Lower portion of induction heater showing the lower portion of the quartz jacket, the $\mathrm{BN}$ and graphite tubes and graphite susceptor.

The top portion of the quartz tube was enlarged to fit a similar aluminum holder which provided an inlet gas connection for the cover gas and a $11 / 8^{\prime \prime}$ round quartz window. The quartz tube was cooled by water flowing through the induction coil and by four air blower fans aimed at the hot zone and ends of the furnace. As a safety precaution, the apparatus was shielded with a plexiglass and copper mesh enclosure. The copper mesh was used to prevent leakage of RF radiation. An overall view of the induction furnace is given in Figure 2.8. 


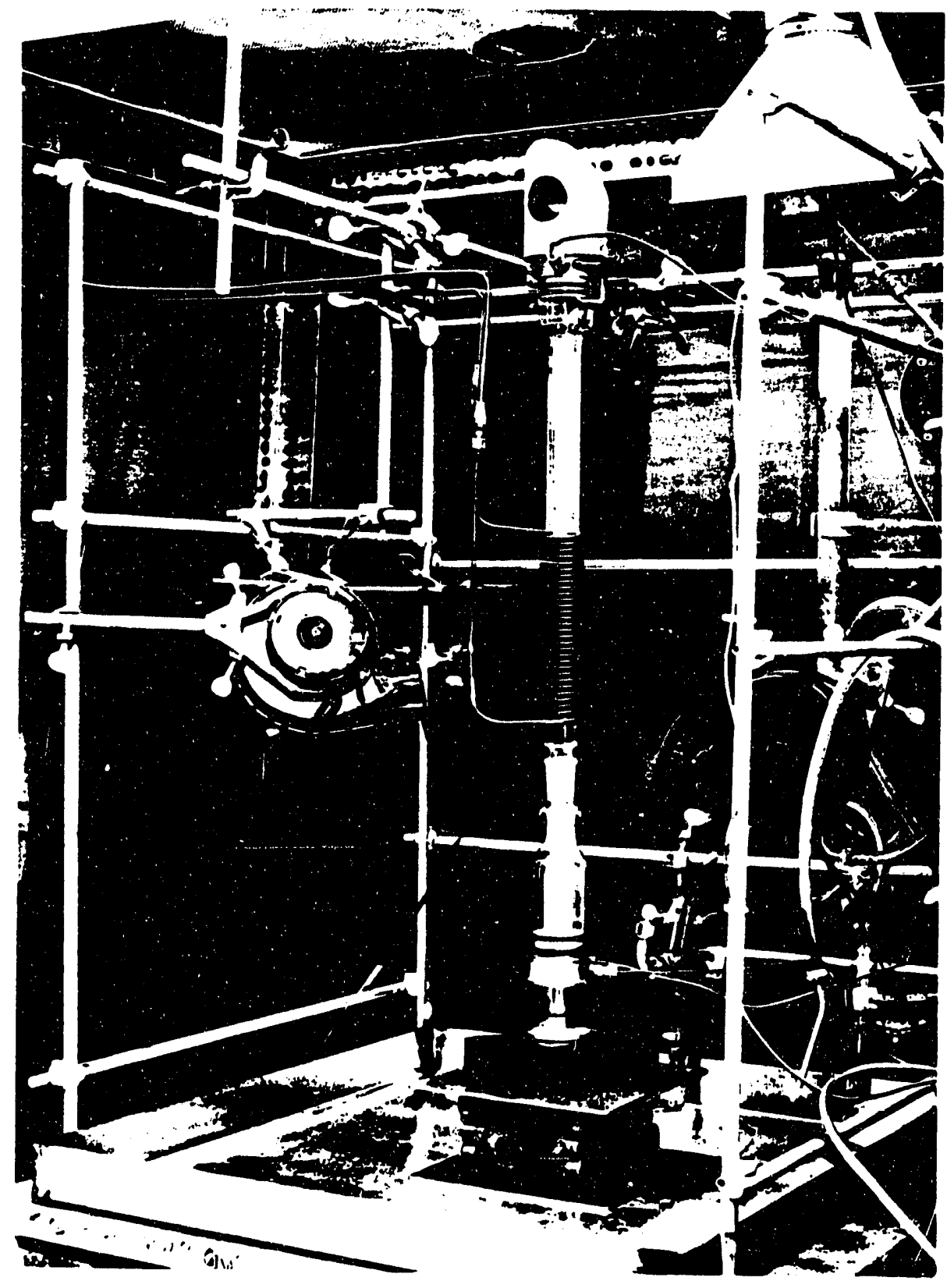

Figure 2.8. Overall view of induction heater showing the coil, outer quartz jacket and end fittings. 


\subsection{Temperature Measurement and Calibration}

All temperatures were measured using an optical pyrometer which was focused onto the sample through the viewing hole in the susceptor, the window atop the quartz jacket and a front surface mirror. The pyrometer and its associated optics (window and mirror) was calibrated using an NBS-certified tungsten strip lamp in accordance with accepted procedures for pyrometer calibration. $^{2}$ In the procedure used, a temperature vs. pyrometer output curve is generated for the low range of the pyrometer, i.e. with no filters or optics. Figure 2.9 shows a typical calibration curve. Each new range or set of optical elements (mirrors and windows) is calibrated by evaluating the so-called "A" value of the absorbing component. Since this is a constant with temperature, a number of determinations can be made and the results averaged. Typical values for these constants are given in Table 2.2. Once these values are obtained, the actual temperature can be calculated analytically from the apparent temperature by the expression

$$
\frac{1}{T_{\text {actual }}}=\frac{1}{T_{\text {apparent }}}-A
$$

$T_{\text {apparent }}$ is itself calculated from a least squares fit of the first range value. For a system with more than one filter, the contribution of the A values are additive.

Table 2.2. Typical "A" values for pyrometer calibration. Data taken for Pyrometer No. 252 which was calibrated on $3 / 9 / 90$.

Optical Element
A - Value $\left(K^{-1}\right)$

$\begin{array}{ll}\text { Range } 2 \text { filter } & 1.84 \times 10^{-4} \pm 1.28 \times 10^{-6} \\ \text { Range } 3 \text { filter } & 3.89 \times 10^{-4} \pm 2.64 \times 10^{-6} \\ \text { Window + Mirror } & 3.00 \times 10^{-5} \pm 1.9 \times 10^{-6}\end{array}$

${ }^{2 H}$. J. Kostkowski and R. D. Lee, Theory and Methods of Optical Pyrometry, National Bureau of Standards Monograph 41, March, 1962. 


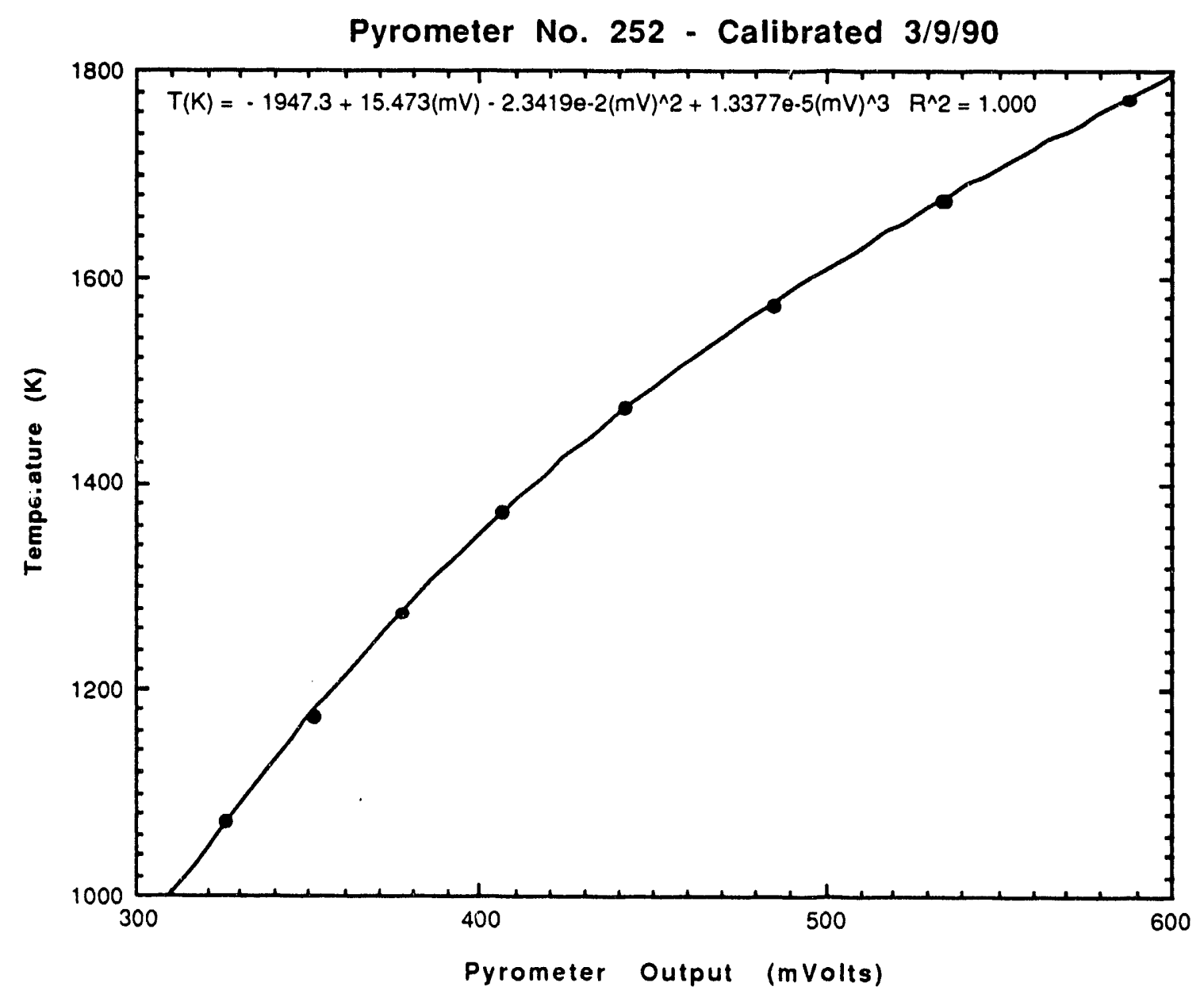

Figure 2.9. Typical calibration curve for range 1 of an optical pyrometer.

In order to verify that the temperatures measured in these experiments were accurately reflecting sample temperatures in the crucible, a number of melting point determinations were made. Samples of three materials were used: $\mathrm{Nb}$ metal (purity unknown), $\mathrm{BeO}(99.5 \%)$ and $\mathrm{Al}_{2} \mathrm{O}_{3}(99.9 \%)$. Samples were heated in the induction furnace in a flowing $\mathrm{He}$ environment. Test pieces were placed inside a $\mathrm{TaC}$ or $\mathrm{NbC}$ crucible with either a tungsten (stable to $2600^{\circ} \mathrm{C}$ ) or molybdenum (stable to $2100^{\circ} \mathrm{C}$ ) liner to prevent sample interaction with the crucible wall. ${ }^{3}$ Heating was provided by an uncoated graphite susceptor.

${ }^{3}$ G. W. Cunningham, "Compatibility of Metal and Ceramics", Proceedings of the Conference on Nuclear Applications of Nonfissionable Ceramics, A. Boltax and J. H. Handwerk, eds., May 9, 1966. 
Two melt series were conducted. Melts in Series A were conducted in an uncapped susceptor so that melting could be observed. Temperatures were measured from a spot at the base of the crucible. Because of geometric and material, i.e. emissivity, differences the sample appeared to be 200 to $300^{\circ} \mathrm{C}$ cooler than this spot. The results of this series are given in Table 2.3. While melting could be directly observed in these tests, non-black body conditions were most likely present. Thus the temperatures recorded were most likely not accurate. In the second group of tests, Series B, the susceptor was capped and the temperature measured through a small hole in the cap to achieve near black body conditions. Since the sample melt could not be observed directly in this arrangement, the melting point was approached by heating the specimen for 5 minutes at a temperature, quenching and inspecting the sample for melt. If the sample melted the heat temperature was recorded as the melting point. If not, the sample was reheated to a higher temperature and the procedure repeated until the sample melted. The temperature increment chosen was roughly $50^{\circ} \mathrm{C}$. The results of these tests are also given in Table 2.3.

These test results indicate a good degree of accuracy for temperature measurement since in the Series $\mathrm{B}$ test melting points agreed to within $50^{\circ} \mathrm{C}$ of the literature values. Further testing in this area will continue, but will focus on fusion point determination ${ }^{4}$ of similar refractory compounds of higher purity.

${ }^{4}$ W.D. Kingery, Property Measurements at High Temperatures, New York, 1959. 
Table 2.3 Results of melting point tests.

\begin{tabular}{|c|c|c|c|c|c|c|c|}
\hline Material & $\begin{array}{l}\text { Sample } \\
\text { Number }\end{array}$ & $\begin{array}{c}\text { Base } \\
\text { Material }\end{array}$ & $\begin{array}{c}\text { Wall } \\
\text { Material }\end{array}$ & $\begin{array}{l}\text { Cap on } \\
\text { Susceptor }\end{array}$ & $\begin{array}{c}\text { Temperature } \\
\left({ }^{\circ} \mathrm{C}\right)\end{array}$ & $\begin{array}{l}\text { Time } \\
\text { (minutes) }\end{array}$ & Melt \\
\hline \multirow[t]{11}{*}{$\mathrm{Nb}$} & 1 & $W$ & - & no & 2474 & $<0.5$ & yes \\
\hline & 2 & $W$ & - & no & 2165 & 5 & no \\
\hline & & & & & 2327 & 5 & no \\
\hline & & & & & 2370 & & \\
\hline & 3 & W & W & no & 2327 & 5 & no \\
\hline & & & & & 2371 & 5 & no \\
\hline & & & & & 2389 & $<0.5$ & yes \\
\hline & 4 & $W$ & $W$ & yes & 2285 & 5 & no \\
\hline & & & & & 2343 & 5 & no \\
\hline & & & & & 2386 & 5 & no \\
\hline & & & & & 2406 & 5 & yes \\
\hline \multirow[t]{10}{*}{$\mathrm{BeO}$} & 1 & W & W & no & 2359 & 1 & no \\
\hline & & & & & 2400 & 1 & no \\
\hline & & & & & 2434 & $<0.5$ & yes \\
\hline & 2 & & & yes & 2400 & 2 & yes \\
\hline & 3 & W & W & yes & 2364 & 5 & yes \\
\hline & 4 & W & W & yes & 2327 & 5 & no \\
\hline & & & & & 2364 & 5 & no** \\
\hline & & & & & $2389-2416$ & 5 & yes \\
\hline & 5 & W & W & yes & 2327 & 5 & yes"*" \\
\hline & 6 & W & W & yes & 2339 & 5 & yes"*" \\
\hline \multirow[t]{4}{*}{$\mathrm{Al}_{2} \mathrm{O}_{3}$} & 1 & W & $W$ & no & 1900 & 1 & no \\
\hline & & & & & 1949 & 1.5 & no \\
\hline & & & & & 2000 & 1.5 & no \\
\hline & & & & & 2063 & 5 & yes*** \\
\hline \multirow[t]{2}{*}{$\mathrm{Al}_{2} \mathrm{O}_{3}$} & 2 & Mo & Mo & yes & 1931 & 5 & no \\
\hline & & & & & 1968 & 5 & yes*** \\
\hline \multirow[t]{2}{*}{$\mathrm{Al}_{2} \mathrm{O}_{3}$} & 3 & W & W & yes & 1968 & 5 & no \\
\hline & 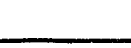 & & & & $2007-2029$ & 5 & yes*"* \\
\hline
\end{tabular}




\subsection{Iest Procedure}

Prior to beginning each test, samples were weighed and measured. In addition a pre-test bakeout was performed by heating the samples in argon for 5 minutes at $\sim 1230 \mathrm{~K}$. Sample and crucible were again weighed. This later weight, which typically was less by a few milligrams than the unheated weight was used as the initial sample weight for subsequent heating tests. After weighing, the samples were placed in the crucible, the crucible placed in the susceptor and the sample purged with $\mathrm{He}$ for a minimum of 15 minutes at a flow rate of $\sim 7 \mathrm{cc} / \mathrm{s}$ and $\sim 15 \mathrm{psig}$. For experiments in which hydrogen was used the sample was first heated to the test temperature under helium purge, the pyrometer aligned and the temperature measured. Typically this took 1 2 minutes. Once the test temperature was reached and the hydrogen flow established, the temperature monitored for the duration of the test. For tests in helium, the sample was brought to temperature under a helium flow of $5-7 \mathrm{cc} / \mathrm{s}$ and $\sim 15 \mathrm{psig}$. The test duration varied, but once completed, the power was turned off and inert gas flow reestablished. The temperature of the sample decreased rapidly to $<1000^{\circ} \mathrm{C}$ in less than one minute. The sample was allowed to cool to room temperature before stopping the purge. The time of the test was recorded, the sample weighed and in some cases measured. If another cycle was required, the procedure described above was repeated until the desired duration at temperature had been reached. Once sample heating was finished final measurements, weights and SEM inspection were conducted. In all cases, multiple weighings of samples and crucible were taken and the results averaged to give a weight at the completion of a cycle. Variations in weight of a few tenths of a milligram were common in the weighings. At the end of each cycle, the quartz tube and window were inspected and cleaned or replaced if necessary. 


\subsection{RESULTS}

\subsection{Iemperatures}

The temperatures measured in these experiments were quite variable. Although a test goal of between 3000 and $3050 \mathrm{~K}$ was sought, larger variation was in fact observed. The mean temperatures for each sample type are given in Table 3.1 while a more detailed temperature history of all samples tested is given in Appendix A.

Table 3.1 Mean temperatures for test specimens.

Material Gas Temperature

$(\mathrm{K})$

1. Carbon-Carbon

FMI material

$\begin{array}{ll}\mathrm{He} & 3043 \pm 12 \\ \mathrm{H}_{2} & 3039 \pm 11 \\ \mathrm{He} & 3053 \pm 58 \\ \mathrm{He} & 3032 \pm 5 \\ \mathrm{H}_{2} & 3035 \pm 10\end{array}$

3. Graphite

$\begin{array}{lll}\text { AFX-5Q } & & \\ \text { Poco Crucibles } & \mathrm{He} & 3017 \pm 42 \\ \text { BNL Crucible } & \mathrm{He} & 3043 \pm 12 \\ \text { AFX-5QI } & \mathrm{He} & 3056 \pm 41 \\ \text { ZFX-5QI } & \mathrm{He} & 2999 \pm 67\end{array}$

\subsection{Hydrogen Tests}

Weight loss data for both carbon-carbon and vitreous carbon specimens are given in Appendix B. As might be expected, both the materials tested showed rather poor resistance to hydrogen. The observed percent weight loss for these samples is given in Figure 3.1. Both the vitreous carbon and carbon-carbon showed a uniform surface attack as well as loss of material from the inside of the sample. Post-test measurement of the sample geometric surface area revealed a decrease in sample size. Post-test measurements of the vitreous carbon sample gave a decrease in the geometric surface area of $24 \%$ after 15 minutes. Similarly, for the carboncarbon specimen, a decrease of $18 \%$ after 5 minutes was found. In addition to an overall loss of sample size, SEM examination revealed an apparent graphitization on the surface of the vitreous carbon sample (see Figure 3.2). The carbon-carbon piece also showed an attack which penetrated below the surface of the specimen. In this case, the binder material was more aggressively attacked than the fibers, leaving behind bare fiber as shown in Figure 3.3. 


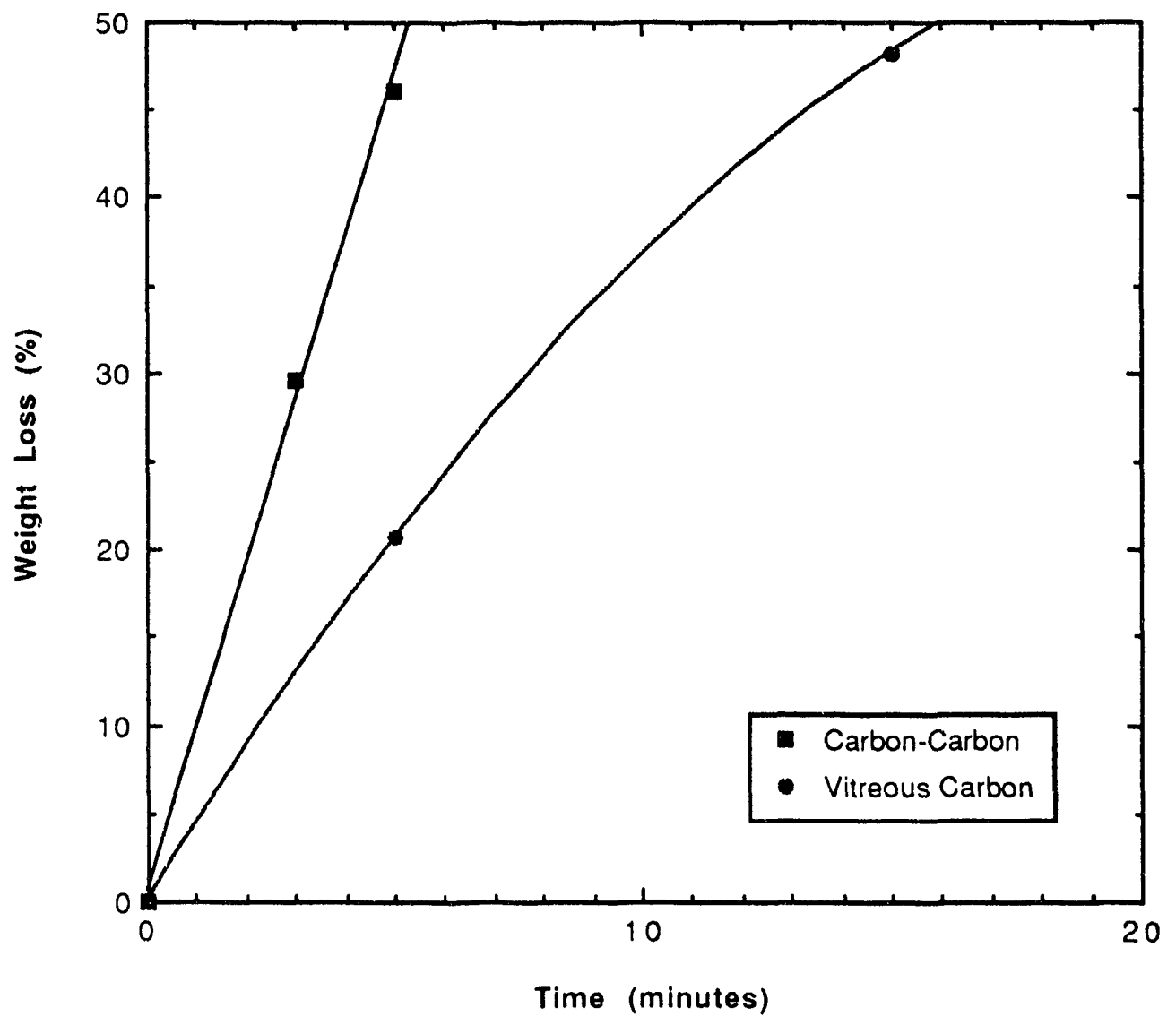

Figure 3.1. Weight loss from vitreous carbon (grade V25) and carbon-carbon after exposure to hydrogen. 


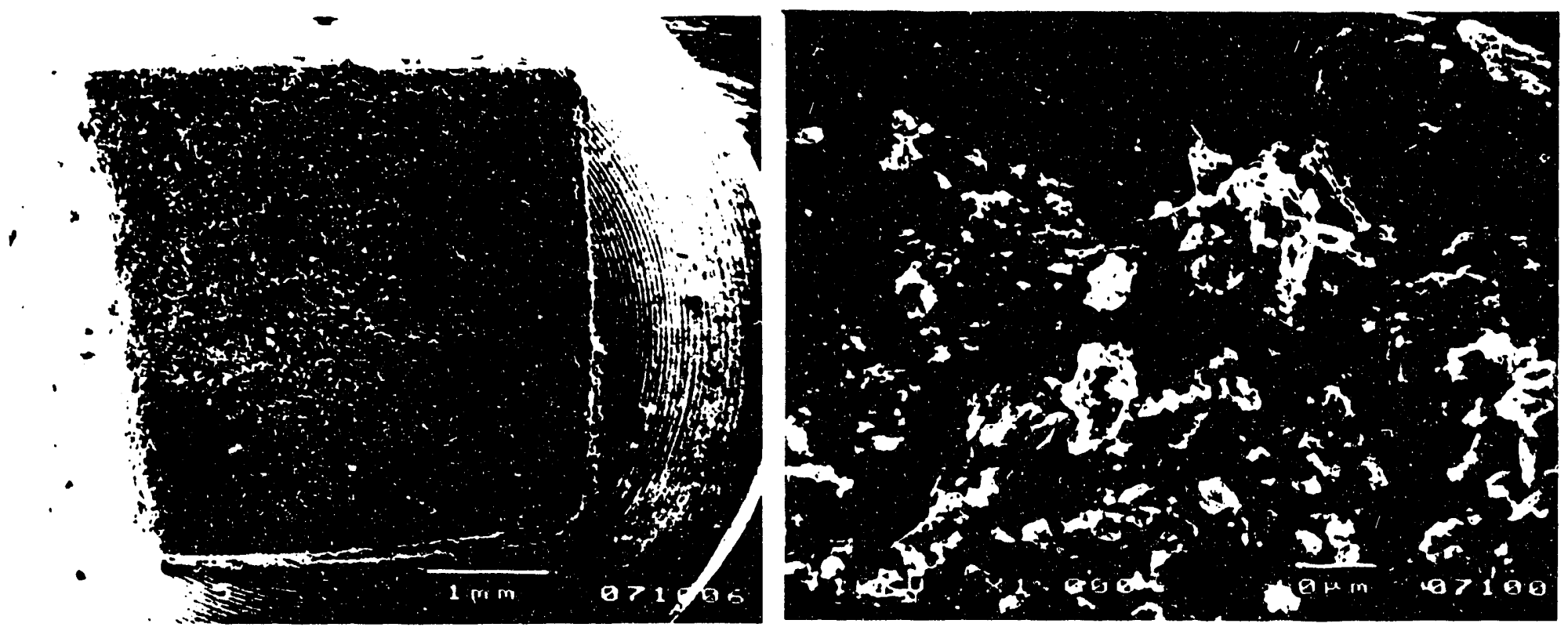

Figure 3.2. Vitreous carbon (grade V25) specimen after 15 minutes in hydrogen.
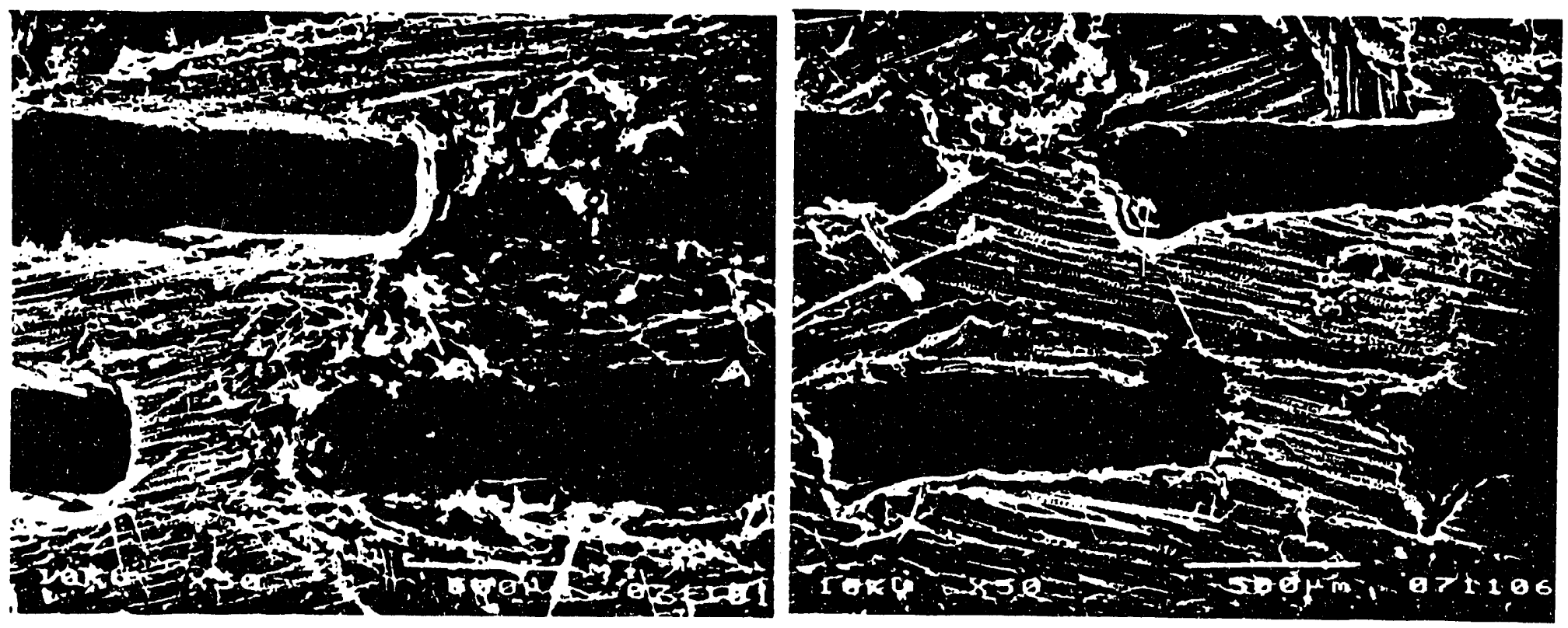

Figure 3.3. Carbon-carbon specimen after 5 minutes in hydrogen. 


\subsection{Helium Tests}

Weight loss data for FMI carbon-carbon, vitreous carbon and graphite specimens are given in Appendix B. The observed percent weight loss for these samples is given in Figure 3.4. In addition, changes in the geometric surtace area of the carbon-carbon samples, the vitreous carbon sample and iwo of the graphite samples (AFX-5QI and ZFX-5QI) are shown in Figure 3.5. The latter should be viewed as estimates since changes in shape(from regular geometric shapes) and surface area (due to holes or slots in the sample) were observed.

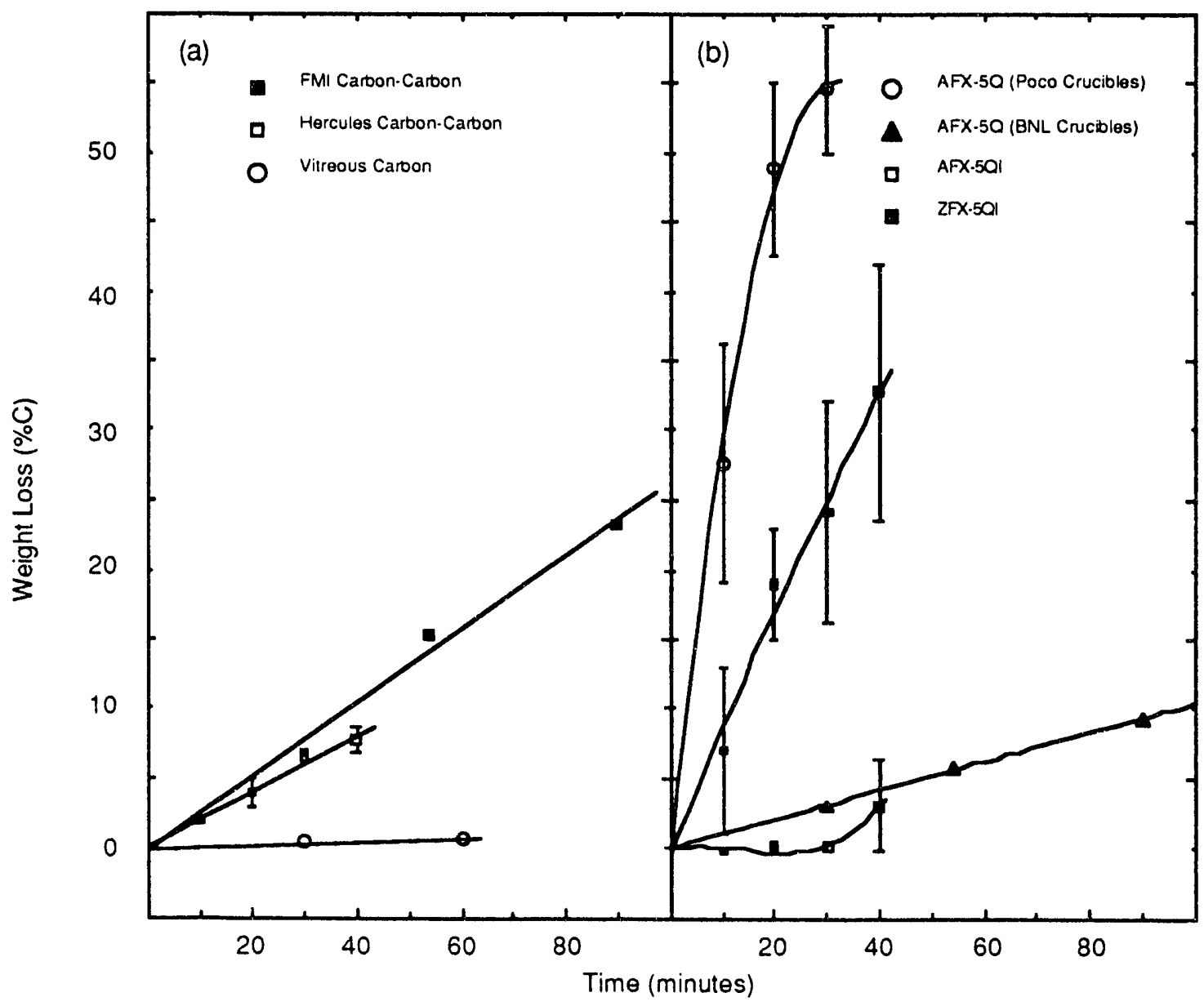

Figure 3.4. Weight losses in helium from (a) carbon-carbon and vitreous carbon samples; and (b) from graphite samples. 


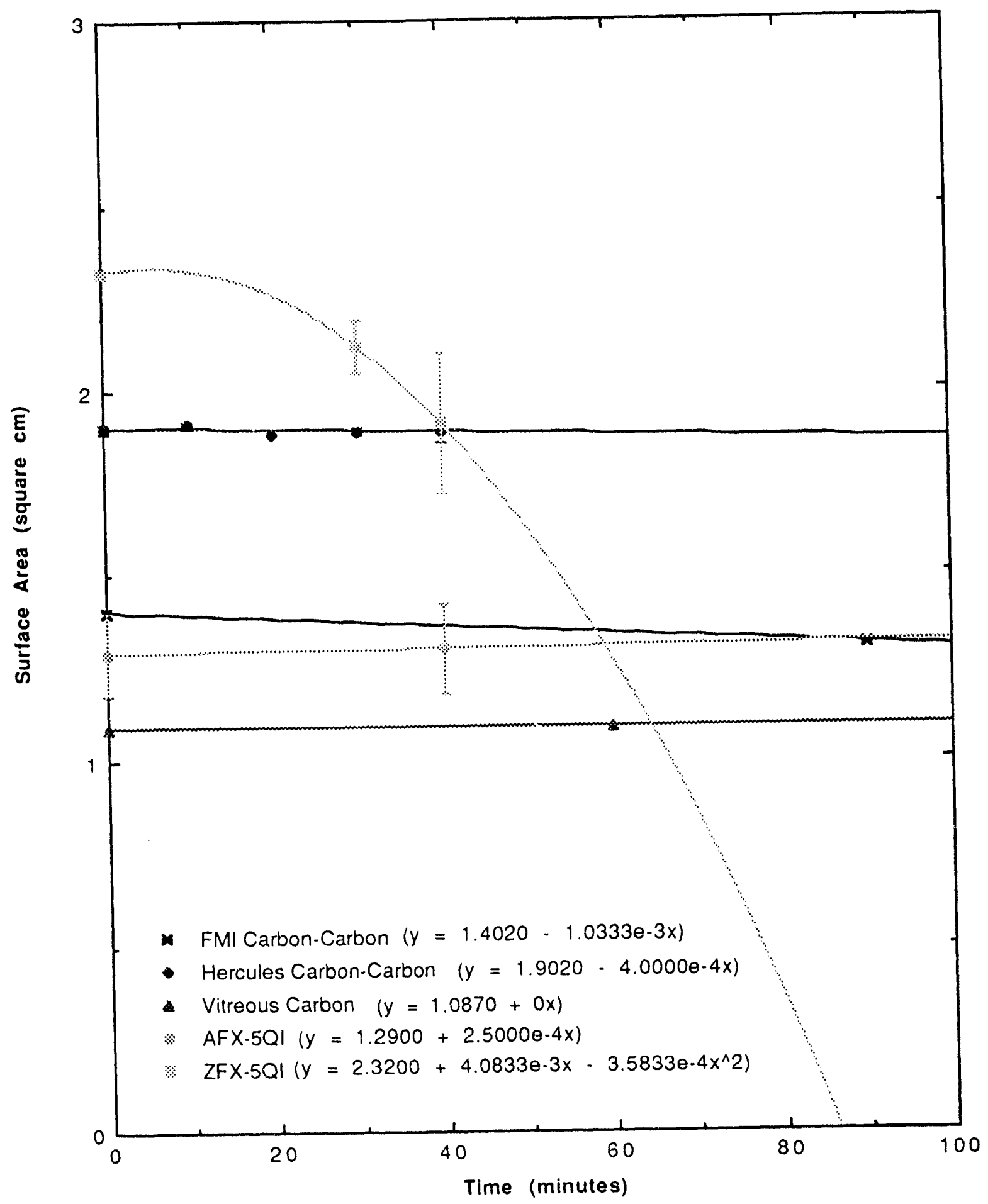

Figure 3.5. Changes in surface area observed for samples heated in flowing helium. 
Several points are evident from these figures. The carbon-carbon samples showed a linear weight loss over the course of the experiments with little if any change in surface area. SEM examination of the samples reveals a possible explanation. As with experiments in hydrogen, material appears to be lost preferentially from the densification medium as opposed to the fibers of the composite. This may be seen readily by comparison of Figure 2.5 with Figure 3.6 and Figure 2.6 with Figure 3.7. The vitreous carbon sample showed almost no weight loss. This is consistent with the lack of change in surface area and microstructure observed. Graphite behavior varied widely with the type of graphite tested: For the unpurified AFX-5Q, large weight losses were seen. In addition, sample thinning and, in some cases, spalling and flaking were evident. Figure 3.8 shows a typical crucible after test. Large sample-to-sample variation was seen in the weight losses observed for this material. Of particular note is the difference in performance of crucibles manufactured by Poco and those made from the same stock here at BNL. The reason for this is unknown. It could be due to batch differences or to differences in the surfaces after machining. Purification appears to lead to a vast improvement in performance. For up to 30 minutes in helium, little if any weight loss is seen for all samples tested. Indeed slight weight gains were observed in some cases. This was apparently due to trace amounts of material from the crucible deposited on the sample which could not be effectively removed prior to weighing. After 40 minutes, significant weight losses were observed in two of the samples tested (5.5-6.2\%) while weight losses for the other two remained small $(0.2-0.3 \%)$. Little change in the surface area of any of these samples was observed. The variation in weight loss between samples may be due to a small stochastic flaking of material which would not be readily apparent in overall dimensional changes. It should be noted in this context that even the largest weight loss observed was only 7 milligrams and for an apparent density of $\sim 1.8 \mathrm{~g} / \mathrm{cm}^{3}$ this would amount to $<4 \times 10^{-3} \mathrm{~cm}^{3}$. A photograph of a posttest specimen is given in Figure 3.8 .
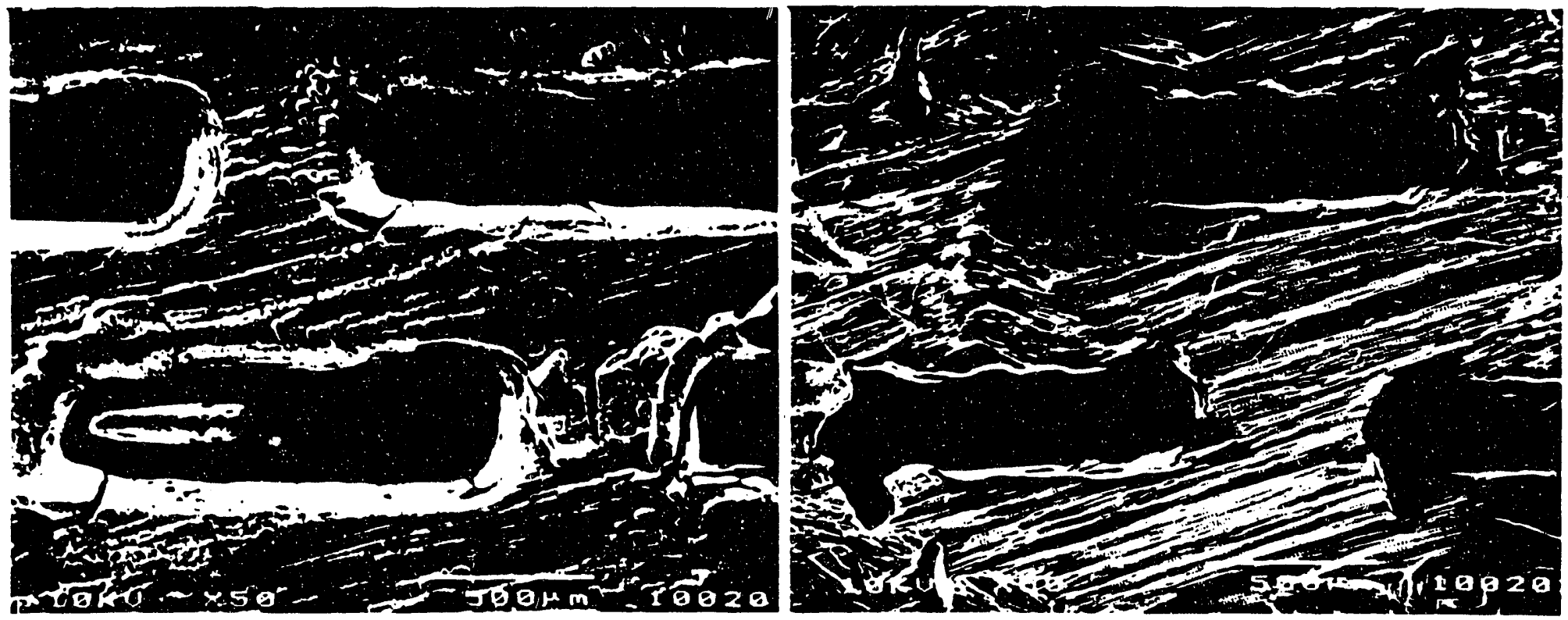

Figure 3.6. FMI carbon-carbon sample after heating in helium for 90 minutes. 

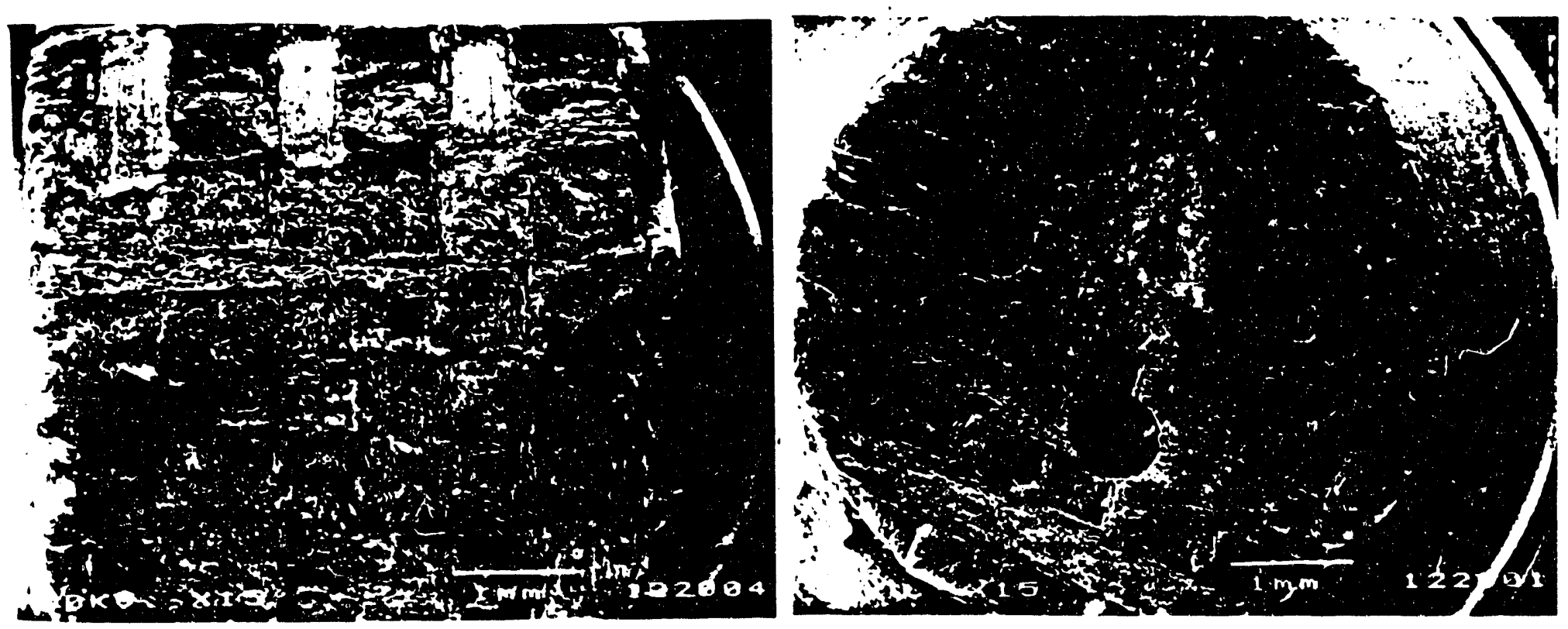

Figure 3.7. Hercules carbon-carbon sample atter heating in helium for 40 minutes.
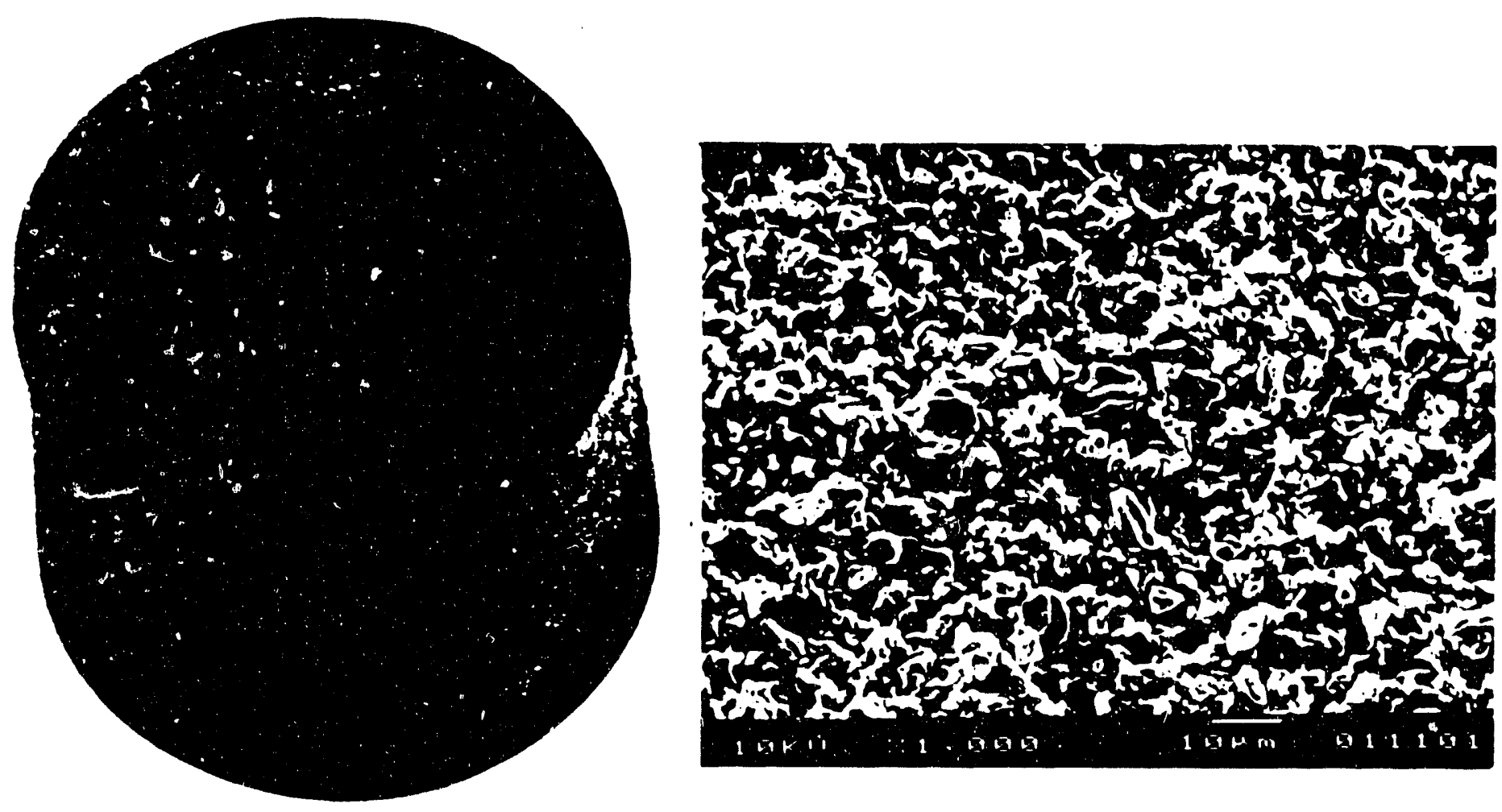

Figure 38 AXF 50 crucible atter 20 minutes in hellum 

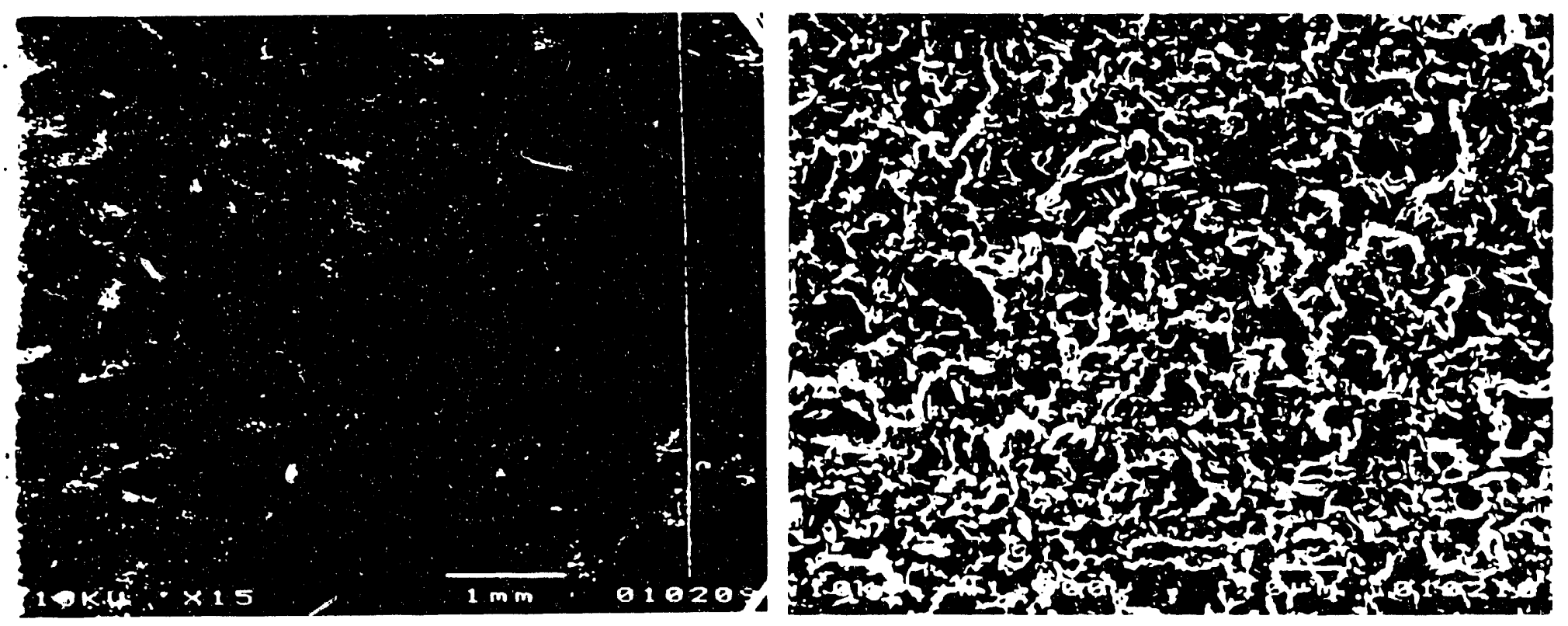

Figure 39 AXF.5Ci sample atter 40 minutes in hellum

The pertomance of the purlted 2XF 501 was most surprizing Large weight losses (in the range of 35\%, were seen n the course of these experments These were accompanted by equally significant changes in sample size: - 10 - decrease in the geometric surtace area.) $A$ polynomial it of the average veight loss vs time figure 34 ) indicates that it is very nearly linear A similar tit of the mean surtace area change Figure 35 ) indicates that the behavior is quadratic. Although estimates of the geometric surtace area are crude. and do not account for deviations from the initial cylindrical nature of the samples. this would indicate inal weight loss trom these samples is not simply controlled oy the geometric surtace area A post.test photograph of a sample is guen in Figure $3 \cdot 0$ This obseriation is supported by comparing the variation in the weight loss observed with the variation in the surtace area Alter to minutes the standard devation of the cutace awa was - 16 . ol the mean while the corresponding value tor the

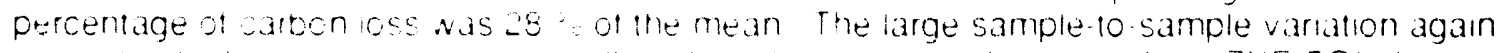
points 10 stochactic frocuses controlling the telease but in the case of the $2 \times F$. 501 the

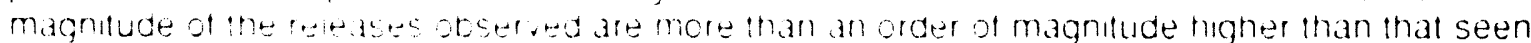
lor the AXF 501 arid corseduentiv of more concern 

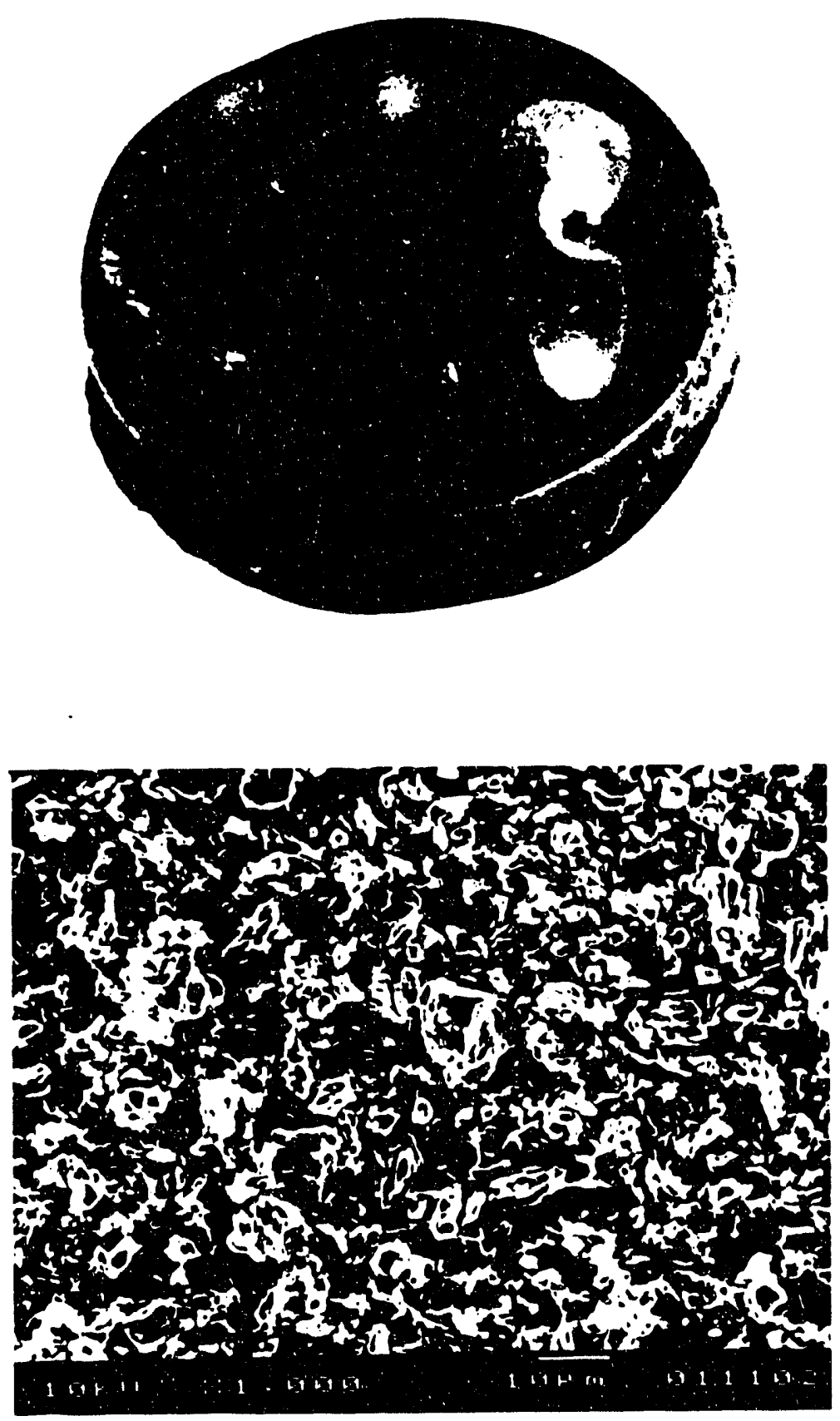

Figure 3.10. ZXF-5Q1 sample after 40 minutes in helium. 


\subsection{DISCUSSION}

The weight loss data presented in the preceding section shows wide variation among types of material (carbon-carbon, vitreous carbon, and graphite), grade of material (e.g. AXF-5QI vs. ZXF-5Q1), material pretreatment (purified vs. unpurified) and even among replicate samples of the same material. In order to account for the differences, the weight loss mechanisms operative should be considered. First, there is the degasing of the material. Second, there is the volatilization of any residual impurities in the graphite. Third, there is the volatilization of the carbon itself at the test temperature. Other physical sources include changes in microstructure and surface characteristics of the samples Each of these will be considered in turn.

All solid carbon will begin to outgas upon heating to temperatures above $1000^{\circ} \mathrm{C}$ releasing gases such as carbon monoxide, carbon dioxide and hydrogen. 5 In a study of the outgasing of AXF-5Q graphites, it has been found that the amount of gas released is dependent upon the length of time the graphite is stored in air. 6 In addition to the gases given by Mantel the release of water, methane and other hydrocarbons were noted. For AXF $-5 Q$, it was found that a total of $2 \times 10^{17}$ molecules $/ \mathrm{g}$ desorbed at $750^{\circ} \mathrm{C}$. At this temperature the major release is due to water. Above $800^{\circ} \mathrm{C}$ to about $1600^{\circ} \mathrm{C}$. Pontau and Morse found significant releases of hydrogen and carbon monoxide. Based upon data in Reference 6, a maximum CO release rate of $3 \times 10^{15}$ molecules/ s/g may be estimated while for hydrogen a value of $5.5 \times 10^{15}$ molecules/ s/g can be inferred. An upper bound to the weight loss this would imply can be estimated by assuming all the gas released below $750^{\circ} \mathrm{C}$ is carbon dioxide since it has the highest molecular weight of the gases released and that maximum air exposure occurred giving a total gas desorbed below $750^{\circ} \mathrm{C}$ of $2 \times 10^{18}$ molecules $/ \mathrm{g}$. The weight of desorbed gas thus calculated from graphite, vitreous carbon and carbon-carbon samples is given in Table 4.1 along with the total weight loss observed. It can be readily seen from this table that weight loss from desorbed gas is one to two orders of magnitude lower than the tolal weight loss actually observed in all cases.

Table 4.1. Amount of gas desorbed from specimens in helium tests using data in Reference 6. Note: it has been assumed that ail gas released below $750^{\circ} \mathrm{C}$ was released as carbon dioxide for the sake of estimating the weight.

\begin{tabular}{|c|c|c|c|c|c|c|}
\hline Material & $\begin{array}{l}\text { Initial } \\
\text { Weight } \\
\text { (g) }\end{array}$ & $\begin{array}{l}\text { Time } \\
\text { (min.) }\end{array}$ & $\begin{array}{c}\text { Gas Release } \\
\text { at } 750^{\circ} \mathrm{C} \\
\text { (g) }\end{array}$ & $\begin{array}{l}\text { Gas Release } \\
750-1600^{\circ} \mathrm{C} \\
\text { (g) }\end{array}$ & $\begin{array}{l}\text { Predicted } \\
\text { Loss } \\
\text { (g) }\end{array}$ & $\begin{array}{l}\text { Actual } \\
\text { Loss } \\
\text { (g) }\end{array}$ \\
\hline arbon-Carbon & & & & & & \\
\hline FMI & 0.1062 & 90 & $1.55 \times 10^{-05}$ & $9.05 \times 10^{-05}$ & $1.06 \times 10^{-04}$ & $2.48 \times 10^{-02}$ \\
\hline Hercules & 0.3617 & 40 & $5.29 \times 10^{-05}$ & $1.37 \times 10^{-04}$ & $1.90 \times 10^{-04}$ & $2.79 \times 10^{-02}$ \\
\hline Vit.Carbon & 0.0863 & 60 & $1.26 \times 10^{-05}$ & $4.90 \times 10^{-05}$ & $6.16 \times 10^{-05}$ & $5.00 \times 10^{-04}$ \\
\hline AXF-5QI & 0.1341 & 40 & $1.96 \times 10^{-05}$ & $5.08 \times 10^{-05}$ & $7.04 \times 10^{-05}$ & $3.55 \times 10^{-03}$ \\
\hline ZXF-5QI & 0.3812 & 40 & $5.57 \times 10^{-05}$ & $1.44 \times 10^{-04}$ & $2.00 \times 10^{-04}$ & $1.58 \times 10^{-01}$ \\
\hline
\end{tabular}

${ }^{5}$ C. L. Mantel, Carbon and Graphite Handbook, Chapter 19, Artificial Graphite, Huntington, 1979, pp 323-83.

${ }^{6}$ A. E. Pontau and D. H. Morse, "Outgasing of AXF-5Q and Other Grades of Limiter Graphites",J. Nucl. Mat. 141-143, 124-130 (1986). 
A second weight loss mechanism is release of volatiles trapped in the carbon as a result of processing. Poco indicates that their typical graphites range from 300-3000 ppm while their purified grades contain less than $5 \mathrm{ppm}$ total impurities. ${ }^{7}$ Even at the highest impurity levels, weight loss from the volatilization of impurities will not account for the weight loss observed. Loss through volatilization could give rise to flaking or spalling of the graphite, however. While this process is likely to be stochastic, it could account for some of the behavior observed in test specimens since it could give rise to a weight loss much higher than that implied by the ash content. This behavior is consistent with the flaking observed particularly on the AFX-5Q as well as the production of a fine graphite dust which was noted on sume samples during the test.

A third weight loss mechanism is vaporization of the carbon itself. Mantel ${ }^{5}$ discusses the free vaporization rate of graphite. This was determined by assuming ideal gas behavior of the carbon vapor the pressure of which at any temperature is calculated from the weighted sum of the partial pressures of the different species present in the gas phase. The data thus derived is presented graphically in Figure 4.1. More recently, Schweitzer and Sastre 8 have reviewed the available literature and arrived at a much lower free vaporization rate. This is also presented in Figure 4.1. It can be seen from this figure that the vaporization rate is a strong function of the temperature. It begins to become significant above $2500^{\circ} \mathrm{C}(2793 \mathrm{~K})$. Using the data provided by Mantel as well as Schweitzer and Sastre, the vaporization rate has been estimated for these experiments and the maximum weight loss expected from vaporization estimated. This is given in Table 4.2. It can be seen that in all cases the free vaporization of carbon would predict a much higher weight loss than was actually observed. In fact, it would predict that the samples should have vaporized entirely. Mantel indicates that these values should be viewed as upper limits. Loss from actual graphites depend upon the resistance to vaporization due to surface energy effects. This is accounted for as a factor applied to the free vaporization rate known as the accommodation coefficient. This coefficient can be quite high. For example, Mantel points out that the contribution of $\mathrm{C}_{3}$ to the vapor phase in crystals of pyrolytic graphite is a factor of 10 lower than predicted. These accommodation factors are not known for the materials studied. Further the degree to which the graphite present in the susceptor and crucible as well as the gas flow rate would effect the result are not known. These factors however could well serve to reduce the effective vaporization rate. Further the effects of pressure and flow rate on the vaporization rate have not been considered. In spite of this, however, it would appear that vaporization alone could account for the weight losses observed in these experiments.

Table 4.2. Estimates of the maximum anticipated weight loss due to carbon vaporization.

\begin{tabular}{c|c|c|c|c|c|c} 
Material & $\begin{array}{c}\text { Surface } \\
\text { Area } \\
\left(\mathrm{cm}^{2}\right)\end{array}$ & $\begin{array}{c}\text { Time } \\
\text { (minutes) }\end{array}$ & $\begin{array}{c}\text { Temperature } \\
(\mathrm{K})\end{array}$ & $\begin{array}{c}\text { Predicted } \\
\text { Loss** } \\
(\mathrm{g})\end{array}$ & $\begin{array}{c}\text { Predicted } \\
\text { Loss** } \\
(\mathrm{g})\end{array}$ & $\begin{array}{c}\text { ActualLos } \\
\mathrm{s}^{*} \\
(\mathrm{~g})\end{array}$ \\
\hline $\begin{array}{c}\text { Carbon-Carbon } \\
\text { FMI }\end{array}$ & 1.4 & 90 & $3043 \pm 12$ & 18.9 & 0.59 & 0.0248 \\
Hercules & 1.9 & 40 & $3053 \pm 58$ & 11.4 & 0.39 & 0.0279 \\
Vitreous Carbon & 1.27 & 60 & $3035 \pm 10$ & 11.43 & 0.33 & 0.0005 \\
Graphite & & & & & & \\
AXF-5QI & 1.3 & 40 & $3056 \pm 41$ & 7.8 & 0.28 & 0.0036 \\
ZXF-5Q & 2.3 & 40 & $2999 \pm 67$ & 8.28 & 0.29 & 0.1582
\end{tabular}

Based on data in Reference 5

"Based on data in Reference 8.

\footnotetext{
7W. H. Brixius,ed., Properties and Characteristics of Graphite, Decatur, 1989.

${ }^{8} \mathrm{D}$. G. Schweitzer and C. Sastre, "Performance of Allotropic forms of Carbon in Hydrogen at High Temperatures", in press.
} 


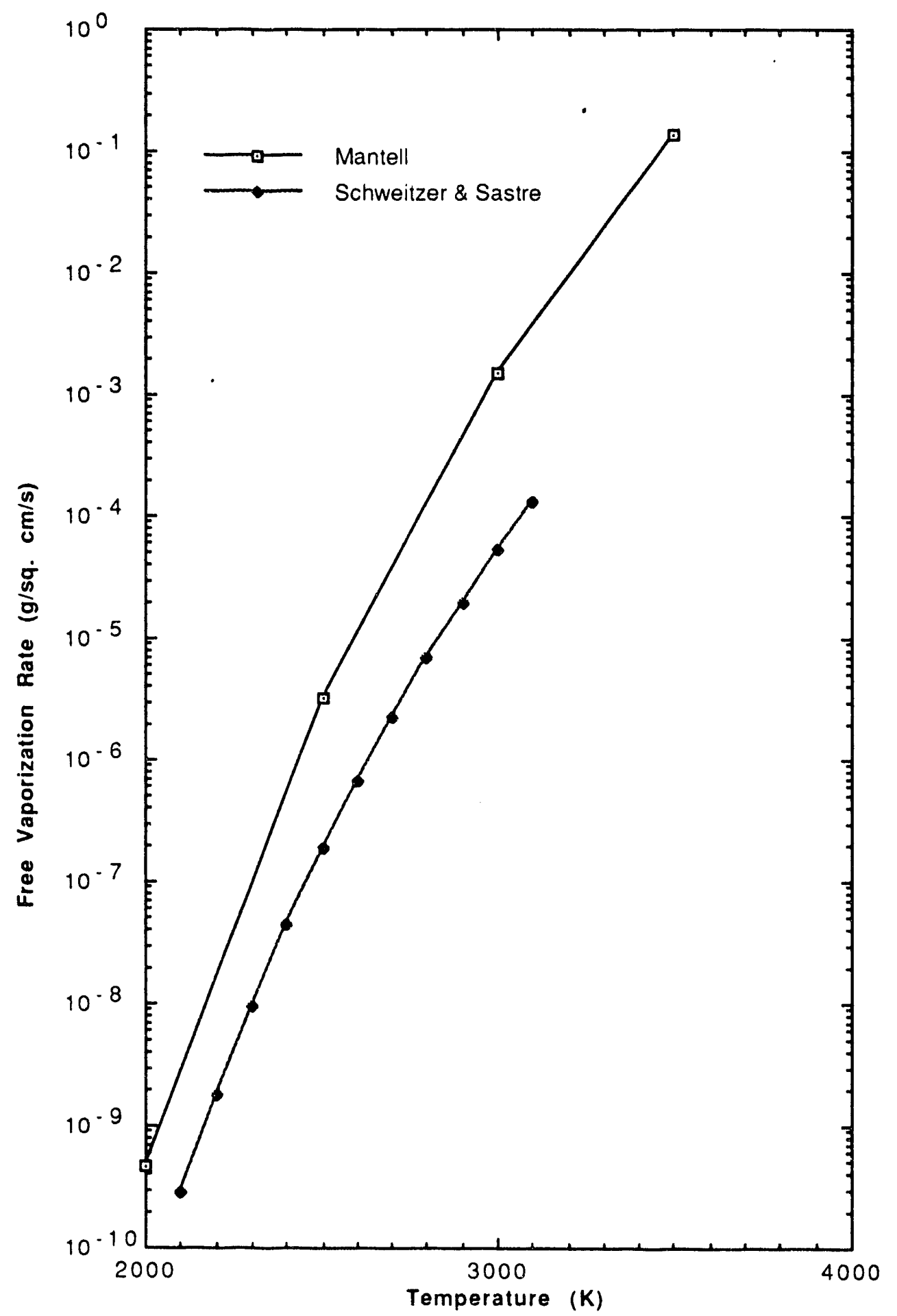

Figure 4.1. Free vaporization rate of artificial graphite. Data taken from References 5 and 8.

Physical differences between sample types as well as samples of similar materials may largely control the relative weight loss of material from the surface and the bulk of the samples tested. Structure (bonding between carbon atoms) and microstructure (porosity, grain size surface roughness, etc.) are both contributing factors. The structures of the 
materials tested are well understood. Both the vitreous carbon and carbon-carbon have a strong 3-dimensional compared to graphite which is essentially planar having only weak van der Waals bonding between planes. Attack along grain boundaries appears to be an important mechanism for some of the graphites tested since microscopic examination revealed that in some cases full grains were removed from the bulk. Further, for the carbon-carbon composites, attack of the fibers was small relative to the loss of binder and intenface material. With respect to microstructural effects, the smooth finish observed on some of the AFX-5QI samples may have contributed to the weight losses observed for this material.

Given this discussion, it would appear that the data obtained herein provide a good measure of the relative performance of carbon-based substrate materials, if nothing else. The graphites investigated appear to have quite variable performance. With the exception of the purified graphite AFX-5QI, the sample-to-sample variation appears to be unacceptably large. For the ZFX5QI, the maximum standard deviation of weight loss observed was $\sim 85 \%$ of the mean value which itself was quite high ( $7 \%$ in 10 minutes). Even for the AFX-5QI, a large sample-tosample variation is observed, but the magnitude of the weight loss is small enough to make this material more acceptable. In this case, however, the loss of material appears to be dominated by stochastic processes and the effect of this fact on hot frit performance should be evaluated.

Carbon-carbon performance appears to be better on the whole than that of graphite, although it was not as good as the vitreous carbon or the purified AFX-5Ol. Given the fact that the binder and densification medium appears to be released preferentially to the fiber, the weight loss of carbon-carbon composites can probably be improved by changes in the densification medium. The two types of material tested thus far appear to behave similarly even though the fibers used for fabrication, the weave and the heat pretreatment of the samples were quite different. Sampleto-sample variation for carbon-carbon composites appears to be much less than for graphites (see Figure 3.4). This in itself would argue for the use of this material as a substrate for hot frits in preference to graphite. More testing on carbon-carbon and the effect of densification medium is planned for the future.

Of the materials tested, vitreous carbon appears to provide the best performance. Only a single specimen was tested in $\mathrm{He}$ so the question of sample-to-sample variation for this material should be investigated if it is to be pursued as candidate substrate material. The superior performance of vitreous carbon points towards its use as a densification medium for carboncarbon as well.

As expected, all carbon-based substrates tested perform very poorly in hydrogen at the temperatures tested. This was not too surprizing, but it was hoped that the improvement in oxidation resistance of vitreous carbon over graphite might carry over with respect to its resistance to attack by hydrogen. The basis for this assumption was the extremely low porosity of vitreous carbon with respect to graphites or carbon-carbon. The use of vitreous carbon as an unprotected hot frit for temperatures in the range of $3000 \mathrm{~K}$ for an extended period of time does not appear to be practical based upon these results. It does, however, appear to react about a factor of two to three times slower than the current baseline carbon-carbon with hydrogen. This improvement, however pales to insignificance when one considers the overall improvement of more than an order of magnitude which can be achieved by coating substrates. In the course of other testing it has been noted that coating also improves the performance of carbon-based substrates in inert gas environments. 


\subsection{CONCLUSIONS}

The results of this work indicate that carbon-carbon performance in inert gas environments is superior to most graphites. Vitreous carbon behavior appears to be best of all and it may have some application as a densification medium. The potential for using vitreous carbon as a substrate material in preference to graphite should also be investigated. Large sample-to-sample variation in graphites appear to be a problem which should be resolved if their use a hot frit substrate is to be pursued. This is particularly true for long-time, multiple-cycle applications. There are implications in this behavior even for coated samples since a vapor pressure build-up behind a coating could exacerbate coating spalling.

Based upon these weight loss experiments, the use of most of the unprotected carbonbased substrates tested is clearly unacceptable for long durations at temperatures above $3000 \mathrm{~K}$ even in an inert gas environment. At these temperatures, weight loss appears to be controlled by carbon vaporization. At lower temperatures, vaporization would be negligible. For example it can be readily seen from Figure 4.1 that, at $2500 \mathrm{~K}$, the free vaporization rate is reduced by more than 3 orders of magnitude. Even at the lower temperatures, however, with graphite the situation is rather more complicated. The large sample-to-sample variation in weight loss observed could be quite important especially if flaking and spalling are a dominant process. At the temperatures in which these tests were performed, the importance of this mechanism relative to vaporization could not be assessed. For AFX-5Q, it was clearly an important component of the weight losses observed. In all cases, coatings can be used to improve substrate performance even in an inert gas environment.

The inert gas data is also relevant to performance in other environments, specifically with respect to performance in a hydrogen environment. Vaporization will still likely be an important mechanism and weight loss will only be exacerbated by reaction with the gas. Although the materials testing in hydrogen reported herein showed that no material performs acceptably in hydrogen and that coating will be required to extend the lifetime of carbon-based hot frits in hydrogen, materials in which flaking or spalling tends to be a problem, e.g. some of the graphites tested, may be unacceptable as substrates in any event.

The results obtained on carbon-carbon appear to be encouraging. Since loss of material from the densification medium is an important component of the weight losses observed, improvements in performance can be sought by changing the densification medium. Further, little change in the geometric surface area over long times was observed. This is worthwhile from a coating adherence standpoint.

In summary, inert gas testing of substrates at high temperature can provide a basis for selection of materials for further coating development tests. Further, the tests reported herein strongly suggest that sample-to-sample variation in graphites is a problem which may limit their application for systems in which high reliability and long term performance is sought. Finally the area of the effect of densification media on the performance of carbon-carbon is one which will be explored further. 
APPENDIX A TEMPERATURE MEASUREMENTS 
A.1 CARBON-CARBON SAMPLES

\section{A.1.1 FMI Carbon-Carbon}

\section{Time \\ (min)}

3

5

30

54

90

Average

\section{A.1.2 Hercules Carbon-Carbon}

Time
(min)

10

20

30

40

Average

Average of all data : $3053 \pm 58 \mathrm{~K}$

A.2 VITREOUS CARBON

Time
$(\mathrm{min})$

Sample 1

Temperature

(K)

$3072 \pm 10$

$3063 \pm 20$

$3078 \pm 13$

$2945 \pm 144$

$3039 \pm 89$

Helium

Temperature

(K)
Hydrogen
Temperature
(K)

$3044 \pm 9$

3031

$3039 \pm 11$ 
A.3 GRAPHITE

\section{A.3.1 AFX-5Q}

A.3.1.1 Poco machined crucibles

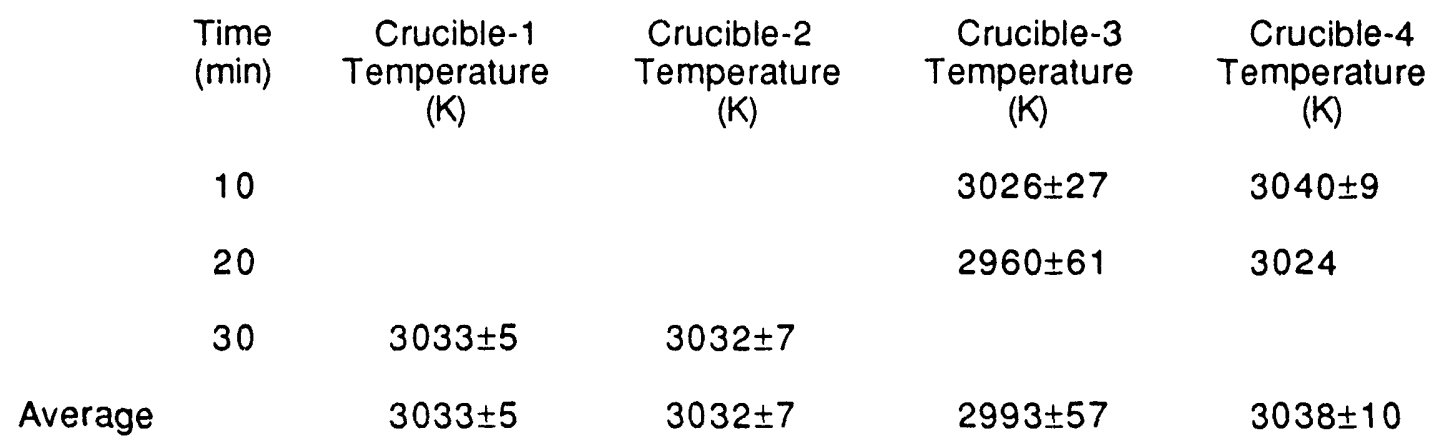

Average of all crucibles : $3017 \pm 42$

A.3.1.2 BNL machined crucible (AFX-5Q*)

$\begin{array}{cc}\begin{array}{c}\text { Time } \\ (\mathrm{min})\end{array} & \begin{array}{c}\text { Temperature } \\ (\mathrm{K})\end{array} \\ 30 & 3044 \pm 9 \\ 54 & 3054 \pm 9 \\ 90 & 3035 \pm 8\end{array}$

Average $\quad 3043 \pm 12$

\section{A.3.2 AFX-501 (purified)}

\begin{tabular}{|c|c|c|c|c|}
\hline $\begin{array}{l}\text { Time } \\
\text { (min) }\end{array}$ & $\begin{array}{c}\text { Sample-1 } \\
\text { Temperature } \\
\text { (K) }\end{array}$ & $\begin{array}{l}\text { Sample-2 } \\
\text { Temperature } \\
\text { (K) }\end{array}$ & $\begin{array}{c}\text { Sample-3 } \\
\text { Temperature } \\
\text { (K) }\end{array}$ & $\begin{array}{c}\text { Sample-4 } \\
\text { Temperature } \\
\text { (K) }\end{array}$ \\
\hline 10 & $3026 \pm 25$ & $3026 \pm 25$ & $3054 \pm 2$ & $3054 \pm 2$ \\
\hline 20 & $2960 \pm 61$ & $2960 \pm 58$ & $3056 \pm 7$ & $3056 \pm 7$ \\
\hline 30 & $3040 \pm 9$ & $3040 \pm 9$ & $3056 \pm 14$ & $3056 \pm 14$ \\
\hline 40 & 3024 & 3024 & $3056 \pm 7$ & $3056 \pm 7$ \\
\hline & $3009 \pm 51$ & $3009 \pm 51$ & $3056 \pm 8$ & $3056 \pm 8$ \\
\hline
\end{tabular}

Average of all samples : $3056 \pm 41$ 
A.3.3 ZFX-501 (purified)

\begin{tabular}{|c|c|c|c|}
\hline $\begin{array}{l}\text { Time } \\
(\min )\end{array}$ & $\begin{array}{c}\text { Sample-1 } \\
\text { Temperature } \\
\text { (K) }\end{array}$ & $\begin{array}{l}\text { Sample-2 } \\
\text { Temperature } \\
(\mathrm{K})\end{array}$ & $\begin{array}{c}\text { Sample-3 } \\
\text { Temperature } \\
\text { (K) }\end{array}$ \\
\hline 10 & $2924 \pm 89$ & $2924 \pm 89$ & $3004 \pm 75$ \\
\hline 20 & $2977 \pm 2$ & $2977 \pm 12$ & $3056 \pm 8$ \\
\hline 30 & $3020 \pm 19$ & $3020 \pm 9$ & $3052 \pm 5$ \\
\hline 40 & $3025 \pm 28$ & $3025 \pm 28$ & $2924 \pm 69$ \\
\hline & $2987 \pm 62$ & $2987 \pm 62$ & $3011 \pm 71$ \\
\hline
\end{tabular}

Average all samples: $2999 \pm 67$ 
APENDIX B WEIGHT LOSS DATA 
B.1 CARBON-CARBON SAMPLES

B.1.1 EMICarbon-Carbon

\begin{tabular}{|c|c|c|c|c|c|c|}
\hline \multirow[b]{2}{*}{$\begin{array}{l}\text { Time } \\
\text { (min) }\end{array}$} & \multicolumn{3}{|c|}{ Helium } & \multicolumn{3}{|c|}{ Hydrogen } \\
\hline & $\begin{array}{l}\text { Weight } \\
\text { (g) }\end{array}$ & ${ }_{(g)}^{W e}$ & $\begin{array}{l}\text { Loss } \\
(\%)\end{array}$ & $\begin{array}{l}\text { Weight } \\
\text { (g) }\end{array}$ & (g) & $\begin{array}{l}\text { ht Loss } \\
(\%)\end{array}$ \\
\hline $\begin{array}{r}0 \\
3 \\
5 \\
30 \\
54 \\
90\end{array}$ & $\begin{array}{c}0.1062 \\
- \\
- \\
0.0990 \\
0.0900 \\
0.0814\end{array}$ & $\begin{array}{c}0 \\
- \\
0.0072 \\
0.0162 \\
0.0248\end{array}$ & $\begin{array}{c}0 \\
- \\
- \\
6.78 \\
15.25 \\
23.35\end{array}$ & $\begin{array}{l}0.0913 \\
0.0642 \\
0.0492\end{array}$ & $\begin{array}{l}0 \\
0.0271 \\
0.0421\end{array}$ & $\begin{array}{l}0 \\
29.68 \\
46.11\end{array}$ \\
\hline
\end{tabular}

B1.2 Hercules Carbon-Carbon

\begin{tabular}{|c|c|c|c|c|c|c|}
\hline \multirow[b]{2}{*}{$\begin{array}{l}\text { Time } \\
\text { (min) }\end{array}$} & \multicolumn{3}{|c|}{ Sample 1} & \multicolumn{3}{|c|}{ Sample 2} \\
\hline & $\begin{array}{l}\text { Weight } \\
\text { (g) }\end{array}$ & (g) & $\begin{array}{l}\text { Loss } \\
(\%)\end{array}$ & $\begin{array}{l}\text { Weight } \\
\text { (g) }\end{array}$ & (g) & $\begin{array}{c}\text { ht Loss } \\
(\%)\end{array}$ \\
\hline $\begin{array}{r}0 \\
10 \\
20 \\
30 \\
40\end{array}$ & $\begin{array}{l}0.3561 \\
0.3495 \\
0.3400 \\
0.3338 \\
0.3318\end{array}$ & $\begin{array}{l}0 \\
0.0066 \\
0.0161 \\
0.0223 \\
0.0243\end{array}$ & $\begin{array}{l}0 \\
1.85 \\
4.52 \\
6.26 \\
6.82\end{array}$ & $\begin{array}{l}0.3662 \\
0.3585 \\
0.3529 \\
0.3423 \\
0.3341\end{array}$ & $\begin{array}{l}0 \\
0.0077 \\
0.0162 \\
0.0239 \\
0.0321\end{array}$ & $\begin{array}{l}0 \\
2.10 \\
4.42 \\
6.53 \\
8.77\end{array}$ \\
\hline
\end{tabular}

\begin{tabular}{c|c|c|c|c}
\multirow{2}{*}{$\begin{array}{c}\text { Time } \\
(\mathrm{min})\end{array}$} & $\begin{array}{c}\text { Weight } \\
(\mathrm{g})\end{array}$ & \multicolumn{2}{|c|}{$\begin{array}{c}\text { Sample 3 } \\
\text { Weight Loss } \\
(\%)\end{array}$} & $\begin{array}{c}\text { Average Weight Loss } \\
(\%)\end{array}$ \\
\hline & & & & \\
0 & 0.3629 & 0 & 0 & 0 \\
10 & 0.3561 & 0.0068 & 1.87 & $1.94 \pm 0.14$ \\
20 & 0.3529 & 0.0100 & 2.76 & $3.90 \pm 0.99$ \\
30 & 0.3396 & 0.0233 & 6.42 & $6.40 \pm 0.13$ \\
40 & 0.3356 & 0.0273 & 7.52 & $7.70 \pm 0.98$
\end{tabular}

B.2 VITREOUS CARBON

\begin{tabular}{|c|c|c|c|c|c|c|}
\hline \multirow[b]{2}{*}{$\begin{array}{l}\text { Time } \\
\text { (min) }\end{array}$} & \multicolumn{3}{|c|}{ Helium } & \multicolumn{3}{|c|}{ Hydrogen } \\
\hline & $\begin{array}{l}\text { Weight } \\
\text { (g) }\end{array}$ & (g) Wei & $\begin{array}{l}\text { oss } \\
(\%)\end{array}$ & $\begin{array}{l}\text { Weight } \\
\text { (g) }\end{array}$ & (g) & $\begin{array}{c}\text { ht Loss } \\
(\%)\end{array}$ \\
\hline $\begin{array}{r}0 \\
5 \\
15 \\
30 \\
60\end{array}$ & $\begin{array}{c}0.0863 \\
- \\
0.0860 \\
0.0858\end{array}$ & $\begin{array}{c}0 \\
- \\
0.0003 \\
0.0005\end{array}$ & $\begin{array}{c}0 \\
\cdot \\
0.35 \\
0.58\end{array}$ & $\begin{array}{l}0.1131 \\
0.0897 \\
0.0585\end{array}$ & $\begin{array}{l}0 \\
0.0234 \\
0.0546\end{array}$ & $\begin{array}{l}0 \\
\text { 20. } 69 \\
48.27\end{array}$ \\
\hline
\end{tabular}




\section{B.3 GRAPHITE}

\section{B.3.1 AFX-50}

B.3.1.1 Poco machined crucibles

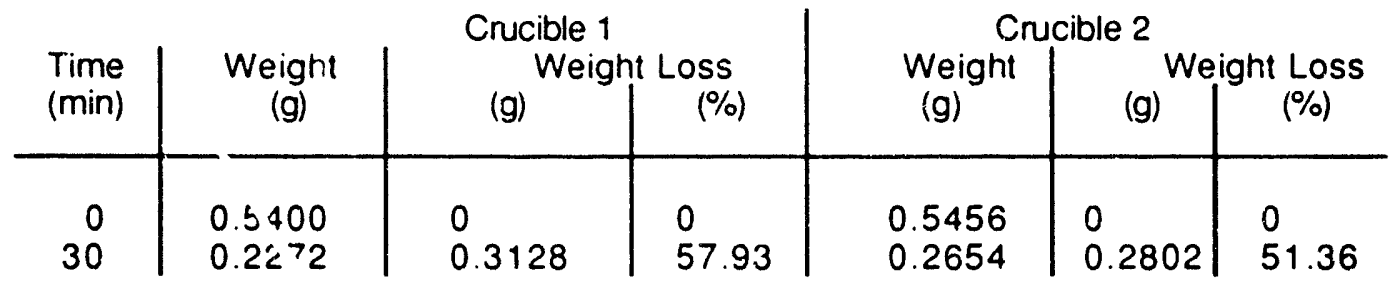

\begin{tabular}{|c|c|c|c|c|c|c|}
\hline \multirow[b]{2}{*}{$\begin{array}{l}\text { Time } \\
\text { (mini) }\end{array}$} & \multicolumn{3}{|c|}{ Crucible 3} & \multicolumn{3}{|c|}{ Crucible 4} \\
\hline & $\begin{array}{l}\text { Weight } \\
\text { (g) }\end{array}$ & (g) $W$ & $\begin{array}{l}\text { Loss } \\
(\%)\end{array}$ & $\begin{array}{l}\text { Weight } \\
\text { (g) }\end{array}$ & (g) & $\begin{array}{l}\text { It Loss } \\
(\%)\end{array}$ \\
\hline $\begin{array}{r}0 \\
10 \\
20\end{array}$ & $\begin{array}{l}0.5373 \\
0.3556 \\
0.2510\end{array}$ & $\begin{array}{l}0 \\
0.1817 \\
0.2863\end{array}$ & $\begin{array}{l}0 \\
33.82 \\
53.28\end{array}$ & $\begin{array}{l}0.541 \\
0.4243 \\
0.3003\end{array}$ & $\begin{array}{l}0 \\
0.1167 \\
0.2407\end{array}$ & $\begin{array}{l}0 \\
21.57 \\
44.49\end{array}$ \\
\hline
\end{tabular}

\begin{tabular}{c|c}
$\begin{array}{c}\text { Time } \\
(\min )\end{array}$ & $\begin{array}{c}\text { Average Weight Loss } \\
(\%)\end{array}$ \\
\hline 0 & 0 \\
10 & $27.69 \pm 8.66$ \\
20 & $48.89 \pm 6.22$ \\
30 & $54.64 \pm 4.65$
\end{tabular}

ษ.1.2 BNL machined crucible (AFX-5Q*)

\begin{tabular}{r|c|c|c} 
Time & Weight & \multicolumn{2}{|c}{ Weight Loss } \\
$(\mathrm{min})$ & $(\mathrm{g})$ & $(\mathrm{g})$ & \\
\hline & & & 0 \\
30 & 1.0300 & 0 & 3.06 \\
54 & 0.9985 & 0.0315 & 5.78 \\
90 & 0.9705 & 0.0595 & 9.29
\end{tabular}




\section{B.3.2 AFX-5Q1 (Purified)}

Note that a negative value for weight loss indicates a slight weight gain. This is most likely due to slight deposits from material lost from either the crucible, susceptor or cover.

\begin{tabular}{|c|c|c|c|c|c|c|}
\hline \multirow{3}{*}{$\begin{array}{l}\text { Time } \\
(\min )\end{array}$} & \multirow{3}{*}{$\begin{array}{l}\text { Weight } \\
\text { (g) }\end{array}$} & \multirow{2}{*}{\multicolumn{2}{|c|}{$\begin{array}{c}\text { Sample } 1 \\
\text { Weight Loss }\end{array}$}} & \multicolumn{3}{|c|}{ Sample 2} \\
\hline & & & & Weight & & Loss \\
\hline & & & & & & (\%) \\
\hline $\begin{array}{r}0 \\
10 \\
20 \\
30 \\
40\end{array}$ & $\begin{array}{l}0.1030 \\
0.1034 \\
0.1034 \\
0.1032 \\
0.0966\end{array}$ & $\begin{array}{l}0 \\
-0.0004 \\
-0.0004 \\
-0.0002 \\
0.0064\end{array}$ & $\begin{array}{l}0 \\
-0.39 \\
-0.39 \\
-0.19 \\
6.21\end{array}$ & $\begin{array}{l}0.127 \\
0.1270 \\
0.1270 \\
0.1270 \\
0.1200\end{array}$ & $\begin{array}{l}0 \\
0 \\
0 \\
0 \\
0.007\end{array}$ & $\begin{array}{l}0 \\
0 \\
0 \\
0 \\
5.51\end{array}$ \\
\hline
\end{tabular}

\begin{tabular}{|c|c|c|c|c|c|c|}
\hline \multirow{3}{*}{$\begin{array}{l}\text { Time } \\
\text { (min) }\end{array}$} & \multirow{3}{*}{$\begin{array}{l}\text { Weight } \\
\text { (g) }\end{array}$} & \multirow{2}{*}{\multicolumn{2}{|c|}{$\begin{array}{l}\text { Sample } 3 \\
\text { Weiaht Loss }\end{array}$}} & \multicolumn{3}{|c|}{ Sample 4} \\
\hline & & & & Weight & & t Loss \\
\hline & & (g) & (\%) & (g) & (g) & (\%) \\
\hline 0 & 0.1505 & 0 & 0 & 0.1559 & 0 & 0 \\
\hline $\begin{array}{l}10 \\
20 \\
30 \\
40\end{array}$ & $\begin{array}{l}0.1505 \\
0.1500 \\
0.1499 \\
0.1502\end{array}$ & $\begin{array}{l}0 \\
0.0005 \\
0.0006 \\
0.0003\end{array}$ & $\begin{array}{l}0 \\
0.33 \\
0.40 \\
0.20\end{array}$ & $\begin{array}{l}0.1560 \\
0.1556 \\
0.1558 \\
0.1554\end{array}$ & $\begin{array}{l}-1 \times 10^{-4} \\
0.0003 \\
0.0001 \\
0.0005\end{array}$ & $\begin{array}{r}-0.06 \\
0.19 \\
0.06 \\
0.32\end{array}$ \\
\hline
\end{tabular}

\begin{tabular}{c|c}
$\begin{array}{c}\text { Time } \\
(\mathrm{min})\end{array}$ & $\begin{array}{c}\text { Average Weight Loss } \\
(\%)\end{array}$ \\
\hline & 0 \\
10 & $-0.11 \pm 0.19$ \\
20 & $0.03 \pm 0.31$ \\
30 & $0.07 \pm 0.25$ \\
40 & $3.06 \pm 3.25$
\end{tabular}


B.3.3 ZFX-5Q1 (Puritied)

\begin{tabular}{|c|c|c|c|c|c|c|}
\hline \multirow[b]{2}{*}{$\begin{array}{l}\text { Time } \\
\text { (min) }\end{array}$} & \multirow[b]{2}{*}{$\begin{array}{l}\text { Weight } \\
\text { (g) }\end{array}$} & \multicolumn{2}{|c|}{ Sample 1} & \multicolumn{3}{|c|}{ Sample 2} \\
\hline & & (g) Weic & $\begin{array}{c}\text {-Oss } \\
(\%)\end{array}$ & $\begin{array}{l}\text { Weight } \\
\text { (g) }\end{array}$ & (g) $W_{e}$ & $\begin{array}{l}\text { ht Loss } \\
(\%)\end{array}$ \\
\hline $\begin{array}{r}0 \\
10 \\
20 \\
30 \\
40\end{array}$ & $\begin{array}{l}0.3938 \\
0.3825 \\
0.3305 \\
0.3186 \\
0.3058\end{array}$ & $\begin{array}{l}0 \\
0.0113 \\
0.0633 \\
0.0752 \\
0.0880\end{array}$ & $\begin{array}{l}0 \\
2.87 \\
16.07 \\
19.10 \\
22.35\end{array}$ & $\begin{array}{l}0.3728 \\
0.3565 \\
0.3083 \\
0.2980 \\
0.2252\end{array}$ & $\begin{array}{l}0 \\
0.0163 \\
0.0645 \\
0.0748 \\
0.1476\end{array}$ & $\begin{array}{c}0 \\
4.37 \\
17.30 \\
20.06 \\
39.59\end{array}$ \\
\hline
\end{tabular}

\begin{tabular}{|c|c|c|c|c|}
\hline $\begin{array}{l}\text { Time } \\
(\min )\end{array}$ & $\begin{array}{l}\text { Weight } \\
\text { (g) }\end{array}$ & $\begin{array}{r}\text { San } \\
\text { Weig }\end{array}$ & $\begin{array}{l}\text { e } 3 \\
\text { Loss } \\
(\%)\end{array}$ & $\begin{array}{c}\text { Average Weight Loss } \\
(\%)\end{array}$ \\
\hline $\begin{array}{r}0 \\
10 \\
20 \\
30 \\
40\end{array}$ & $\begin{array}{l}0.3770 \\
0.3248 \\
0.2883 \\
0.2517 \\
0.2389\end{array}$ & $\begin{array}{l}0 \\
0.0522 \\
0.0887 \\
0.1253 \\
0.1381\end{array}$ & $\begin{array}{c}0 \\
13.85 \\
23.53 \\
33.24 \\
36.63\end{array}$ & $\begin{array}{c}0 \\
7.03 \pm 5.95 \\
18.97 \pm 4.00 \\
24.13 \pm 7.90 \\
32.86 \pm 9.22\end{array}$ \\
\hline
\end{tabular}



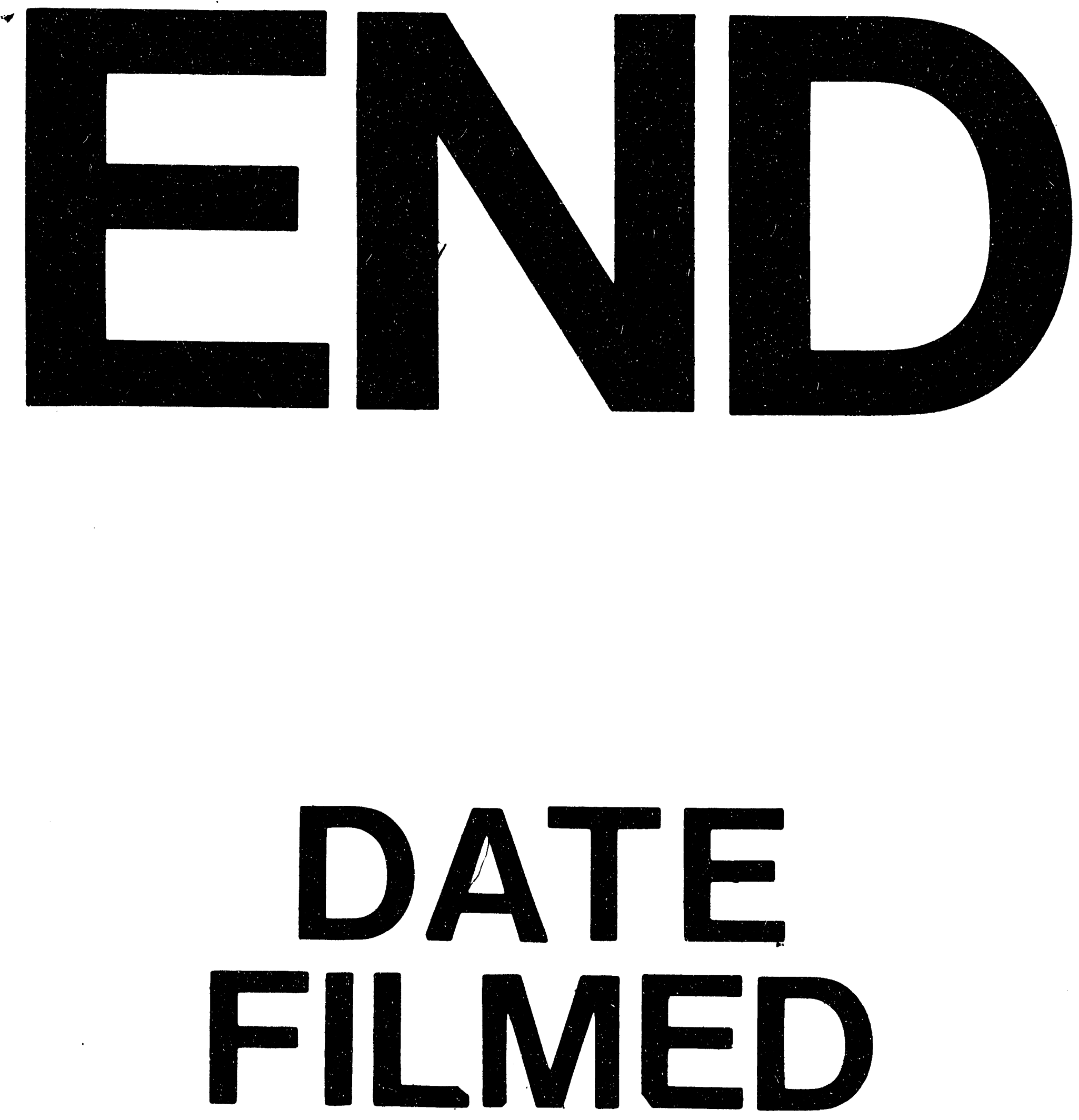

1

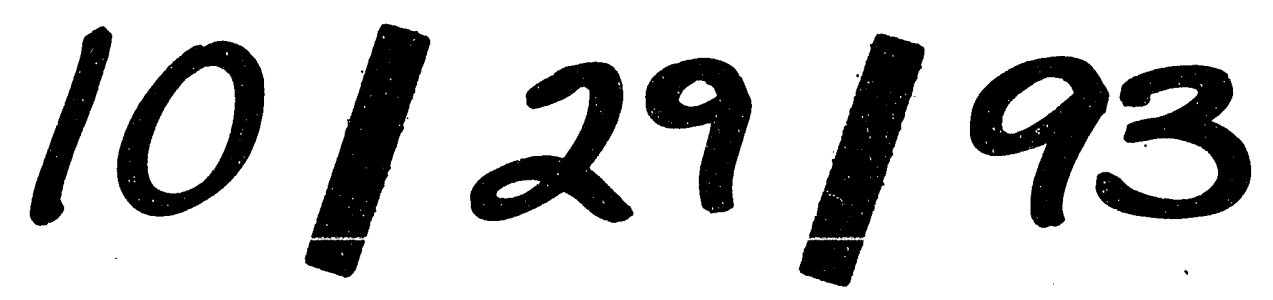




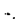

